\title{
ASP Flooding: Theory and Practice Progress in China
}

\author{
Hu Guo, Yiqiang Li, Fuyong Wang, Zhaoyan Yu, Zhiwei Chen, \\ Yansheng Wang, and Xian Gao
}

China University of Petroleum-Beijing, Beijing, China

Correspondence should be addressed to Hu Guo; truetutors@126.com

Received 29 October 2016; Accepted 12 January 2017; Published 28 February 2017

Academic Editor: Debasis Behera

Copyright (C) $2017 \mathrm{Hu}$ Guo et al. This is an open access article distributed under the Creative Commons Attribution License, which permits unrestricted use, distribution, and reproduction in any medium, provided the original work is properly cited.

\begin{abstract}
In low oil price era, it seems that ASP flooding has little market. However, ASP progress in China shows that ASP flooding is good technology to help oil companies thrive and make profit. Since 2014, ASP flooding has entered industrial application in Daqing oilfield. ASP flooding production in 2015 is 3.5 million ton, 9\% of the oilfield's total production of Daqing oilfield. There are 22 ASP flooding blocks in Daqing, containing 7231 wells and 3 are new blocks in 2016. Obviously, more and more ASP flooding is being carried out. Another large ASP flooding field test in high temperature $\left(80^{\circ} \mathrm{C}\right)$ in Henan oilfield has got staged incremental oil recovery of 7.7\%. Latest theory and application in ASP flooding in China are reviewed to help ASP flooding go from success to more application. Weak alkali is better than strong alkali ASP flooding. Relation between viscosity and IFT is discussed. This paper also explains why weak alkali ASP flooding is promoted in Daqing after 12 field tests on strong alkali one. ASP flooding can be a great help to survive low oil price.
\end{abstract}

\section{Introduction}

Alkali-Surfactant-Polymer (ASP) flooding, proposed based on the polymer flooding, is one of the most promising Chemical Enhanced Oil Recovery (EOR) methods. A good review about chemical EOR can be seen in [1]. Through injecting polymer, surfactant and alkali at the same time, ASP flooding is designed to both improve displacement efficiency and expand sweep efficiency. Polymer is used for improving mobility ratio which greatly contributes to the expansion of sweep efficiency [2]. The use of the alkali and the surfactant is to reduce interfacial tension between the displacing phase and the oil phase so as to improve the oil displacement efficiency. Alkali could also reduce the adsorption of expensive surfactants. Typical alkali and surfactant selection as well as ASP slug design can be referred $[3,4]$. Since the system was first put forward in 1977, extensive researches have been carried out, among which the work done by scholars in China deserves to be noticed. Not only a large number of laboratory experiments but also many field tests have been carried out. According to literature, there were 32 field tests, 19 of which are in China, 7 in the United States, and 3 in Canada [5]. Latest data indicate that 14 field tests and industrial applications were implemented between 2013 and 2015, covering 4495 wells. ASP flooding has entered into commercial application in Daqing since 2014, making China the first and only industrial application country in the world up to present. The ASP flooding product in Daqing of 2015 is 3.5 million ton, 9 percent of total oil production in Daqing oilfield. In 2016, there are 22 ASP flooding industrial blocks in Daqing, covering 7231 injectors and producers. Three new ASP flooding blocks are implemented in 2016. Considering the low oil price, this is of special value. After decades of efforts, the theory barrier that the low acid value Daqing oil is not suitable for ASP flooding has been broken. Economical surfactants were produced domestically and optimal well spacing, layer-based composition, and injection parameters were identified. Scaling and produced fluid emulsion dealing difficulties have been overcome, which provided guarantee for industrial application. After comparison of strong alkali and weak alkali ASP flooding field tests performances, weak alkali ASP flooding was considered better choice in current low oil price era, although strong alkali ASP flooding can be very technically and economically feasible in Daqing oilfield. 
Theory and practice progress in China helps in recovery confidence of ASP flooding in extremely low oil price era and most importantly helps oil companies to survive the winter.

\section{Laboratory Study}

2.1. Basic Principle. The recovery efficiency of a flood is conventionally decomposed into the product of the volumetric sweep efficiency and displacement efficiency [16]. The addiction of polymer can increase the viscosity of injection water so as to improve the mobility ratio between the displacement and displaced phases, which is the basic principle of ASP flooding. Meanwhile, in order to improve the displacement efficiency, the surfactant and alkali are used to reduce the interfacial tension (IFT) between the displacement water and the displaced oil phase; mobility ratio, presented as (1), is the ratio of displacing phase (water) and displaced phase (oil). Generally speaking, mobility ratio less than 1 can make the best recovery efficiency [5]. Laboratory experiment research [17] showed that recovery increased with the decreasing of mobility ratio despite the cores being homogeneous or heterogeneous. The recovery of heterogeneous cores is much higher than that of homogeneous cores, and as for heterogeneous cores the flow ratio of ASP flooding and polymer flooding should be controlled at $0.50 \sim 0.25$ while, for its counterpart, the value is suggested to be $0.50 \sim 0.33$. There are several expressions to characterize the capillary number that indicates the ratio of the driving force and resistance. The simplest one taking wettability into account can be shown below as $(2)[18,19]$. Generally, the greater the capillary number, the lower the residual oil saturation [18-22] and the better the oil displacement efficiency. When the capillary number was less than the critical value, the residual oil saturation decreased with the increasing of capillary number, though not drastically; when the capillary number was greater than the critical value, the residual oil saturation would decrease considerably as capillary number increases. As the capillary number reached $10^{-2}$, almost all the remaining/residual oil can be extracted [20]. In order to maximize the recovery, capillary number is required to be enhanced to $10^{-2}$, which may be achieved through increasing the displacement relative viscosity and seepage velocity, or through reducing the IFT between the displacing and displaced phase theoretically. With the increase of the capillary number, the permeability of oil and water was improved and that of the oil phase increased greater. It can make the intersection of the relative permeability curves shift to the right with the increasing of capillary number so that the flow volume of the oil phase can be raised [23].

$$
M=\frac{\lambda_{w}}{\lambda_{o}}=\frac{k_{w} / \mu_{w}}{k_{o} / \mu_{o}},
$$

where $\lambda_{w}$ and $\lambda_{o}$ are the respective mobility of water and oil; $k_{w}$ and $k_{o}$ are the respective permeability of water and oil; $\mu_{w}$ and $\mu_{o}$ are the respective viscosity of water and oil.

$$
N_{c}=\frac{v \mu}{\sigma \cos \theta}
$$

where $\mu$ is the displacing fluid; $v$ is the displacing Darcy velocity; $\theta$ is the contact angle; and $\sigma$ is the IFT between the displacing (water) and the displaced fluid (oil).

Mobility control and capillary number theory were the base of chemical flooding including ASP flooding. Most studies about ASP flooding can be attributed to these two aspects. As for mobility control, the key is the type, concentration, and amount of polymer used to attain proper viscosity ratio or mobility ratio to prevent fingering or channeling. The microscopic and macroscopic sweep efficiency difference can be seen in [24]. As for capillary number, focus is on reduced interfacial tension by surfactants and sometimes alkali. The physical and chemical effect between injected chemicals and rock as well as brine and oil is the main content of ASP flooding research. EOR processes are, in general, designed to overcome the poor mobility ratio and/or the trapping by capillary forces [16].

2.2. Polymer and Displacement Efficiency. Polymer, as an important part of the ASP flooding, is mainly used to increase the viscosity of the injection system and thus improve the mobility ratio. Although there were reports on polymer viscoelastic flooding, the main parameter of the polymer solution in EOR is its viscosity. The viscosity ratio between water and oil greater than 2 is a brief and necessary condition of incremental oil recovery of $20 \%$ in Daqing oilfield ASP flooding [25]. But in the field tests, with the shear degradation taken into account, the water-oil viscosity ratio is generally set to be larger than 3 4. All injection viscosities of ASP in field tests and commercially produced are more than three times of oil viscosity in Daqing. Besides the conventional polymer HPAM, there are modified polymers used in ASP flooding [26]. Associate polymer draws more and more attention recently due to its much lower concentration (about 1/3) to get comparable incremental recovery [27]. For conventional polymer HPAM, more attention is paid to its salinity and alkali's effect on the viscosity. The modified polymers, like hydrophobic associating polymer (like APP4) and comb shape polymer (like KYPAM), which are based on conventional polymer, are designed to achieve better technical and economic indexes. Figure 1 [6] showed comb shape polymer KYPAM viscosity in comparison with typical HPAM. The temperature in Figure 1 is $90^{\circ} \mathrm{C}$ and the salinity is $35000 \mathrm{mg} / \mathrm{L}$. Introducing branched chain with certain functions to the main chain can largely increase its temperature and salt tolerance and viscosity. Researches on the polymer used in ASP flooding [26] focused more on the synthesis of more economic polymer, the effect of polymer in enhancing oil displacement efficiency, and the sweep efficiency, as well as the role of polymer in the ASP flooding.

Luo et al. [28] carried out a research showing the excellent flooding performance of comb shape polyacrylamide KYPAM. It was a copolymer of acrylamide and the new salt monomer (AHPE), with good salt tolerance and increasing viscosity. Compared to conventional polymer under various conditions, the viscosity of KYPAM can be over $22 \%$ to $81 \%$ higher. Meanwhile, the higher the salinity, the greater the super amplitude of viscosity. The KYPAM has an advantage in 


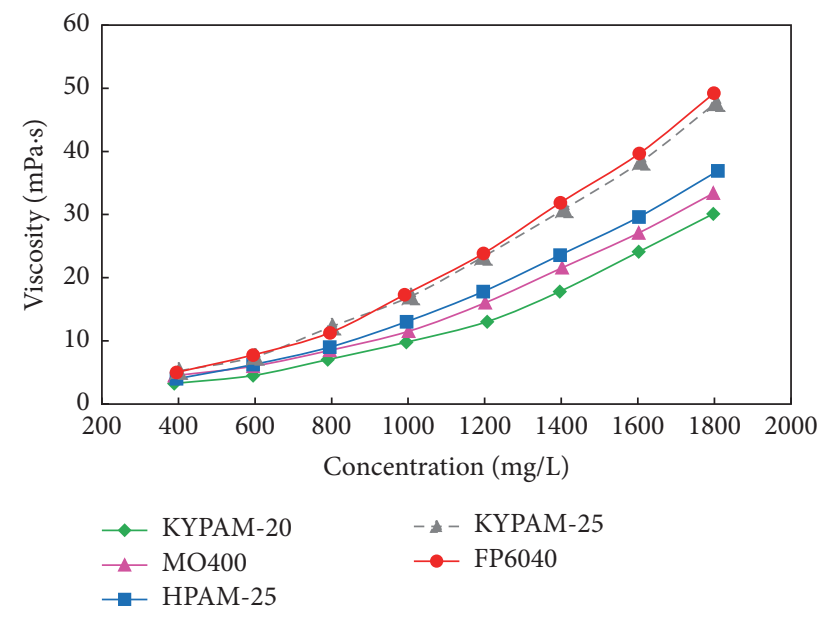

FIGURE 1: Viscosity of different polymers [6].

shear stability, thermal stability, and elasticity over ultrahigh molar mass HPAM. The ASP field test in Xinjiang, Daqing oilfield showed that $43 \%$ of polymer can be saved by using KYPAM rather than HPAM.

Polymer function, as a component of ASP, is very important. It has been commonly agreed on that polymer can improve sweep efficiency [24]. But its ability to improve oil displacement efficiency or reduce residual oil saturation remains controversial for years. It is argued that the capillary number cannot be increased by the polymer, which is the key factor in EOR, so as to fail to improve oil displacement efficiency. Compared to water flooding, polymer flooding cannot decrease the residual oil saturation [29], (Ye et al., 2000). Although it is believed by some scholars that in relative permeability curves polymer flooding has $5 \%$ lower residual oil saturation than water flooding [30], the impact of its sweep efficiency cannot be excluded. It can also be seen from two wells drilled in 7 years apart and at a distance of 30 meters that the maximum oil displacement efficiency was nearly the same without taking sweep efficiency into consideration (Zhao et al. 2000). That is to say, the polymer's effect on reducing residual oil saturation is very tiny. In fact, Koh et al. [31] reported experimental data that are in good agreement with the fractional flow analysis using the assumptions that the true residual oil saturations and end point relative permeabilities are the same for both water and polymer. In other words, both polymer and water flooding relative permeability curve are the same; thus polymer cannot reduce residual oil saturation.

In contrast, it is also believed that polymer flooding can not only improve sweep efficiency, but also improve oil displacement efficiency $[7,32,33]$. The conclusion can be supported by several reasons. The polymer solution is nonNewtonian fluid which does not apply to capillary number theory [34]. However, Seright et al. [35] claimed that under practical conditions for chemical flooding field applications, HPAM solutions show Newtonian or near-Newtonian behavior at low flux values, if ultrahigh-MW polymer species are not present. Wang et al. [7, 32-34] believed that the viscoelasticity of polymer can improve the microscopic oil displacement efficiency and Newtonian fluid and viscoelastic polymer have different velocity distributions in the pores as the front of viscoelastic fluid velocity profile is gentler and the velocity gradient near wall is bigger. In the process of displacement, its ability to strip oil film is better than that of Newtonian fluid. Pull-push effect of the polymer can drive out of the residual oil in dead end area $[7,33]$, as can be seen in Figure 2. They reported a recovery enhancement greater than predicted from the increase in capillary number [33]. The rolling action of the first normal stress and shear stress produced by viscoelastic polymer is bigger than that produced by Newtonian fluid with the same viscosity, and it could be more beneficial to make use of the effect of viscoelastic polymer. In China, many researchers accepted this conclusion, although the experiment needs to be further validated and analyzed.

This argument on polymer's effect on residual oil saturation involves the concept of sweep efficiency and displacement efficiency. Sweep efficiency refers to the ratio of water spreading area to the whole area. Displacement efficiency is limited by residual oil saturation Sor, which in turn is determined by the balance between mobilizing (viscous) and trapping (capillary) forces on disconnected oil ganglia [16]. The displacement efficiency should be referred to residual oil saturation reduction after water injection and should not take remaining oil saturation change after water flooding into consideration. The displacement efficiency, corresponding to sweep efficiency, refers to the changes of residual rather than remaining oil saturation when sweep efficiency reaches $100 \%$. When displacement efficiency is discussed in depth, the effect of sweep efficiency should be excluded. The heterogeneity in cores makes it difficult to distinguish remaining oil and residual oil. The displacement efficiency can be calculated from relative permeability parameter. However, due to the effect of sweep efficiency, displacement efficiency can only be measured accurately by monitoring the change of produced oil volume after polymer was injected in the condition that the water ratio reached $100 \%$ in columnar core water flood experiment. This can be reflected in the different amount of residual oil saturation reduction in the relative permeability curves of polymer and water. The recovery percent obtained by different research methods showed that produced oil driven by polymer is remaining oil after water flooding rather than residual oil because in most experiments polymer is injected when water ratio reached $98 \%$ according to Daqing experiment requirement. Besides, in actual experiment, it takes very long time to make water cut going from $98 \%$ to $100 \%$ and the accuracy requirement is demanding after water cut goes to $98 \%$. At a core scale it is generally difficult to distinguish between water cut $=1.000$ and water cut $=0.995$ and the difference in saturation at water cut $99.5 \%$ and $100 \%$ may be significant [36]. It proved that polymer cannot increase displacement efficiency. That is to say, polymer cannot reduce residual oil saturation. Whether the polymer can reduce residual oil saturation and increase displacement efficiency or not is still in debate; it is widely accepted that ASP flooding can improve sweep efficiency as well as displacement efficiency. 

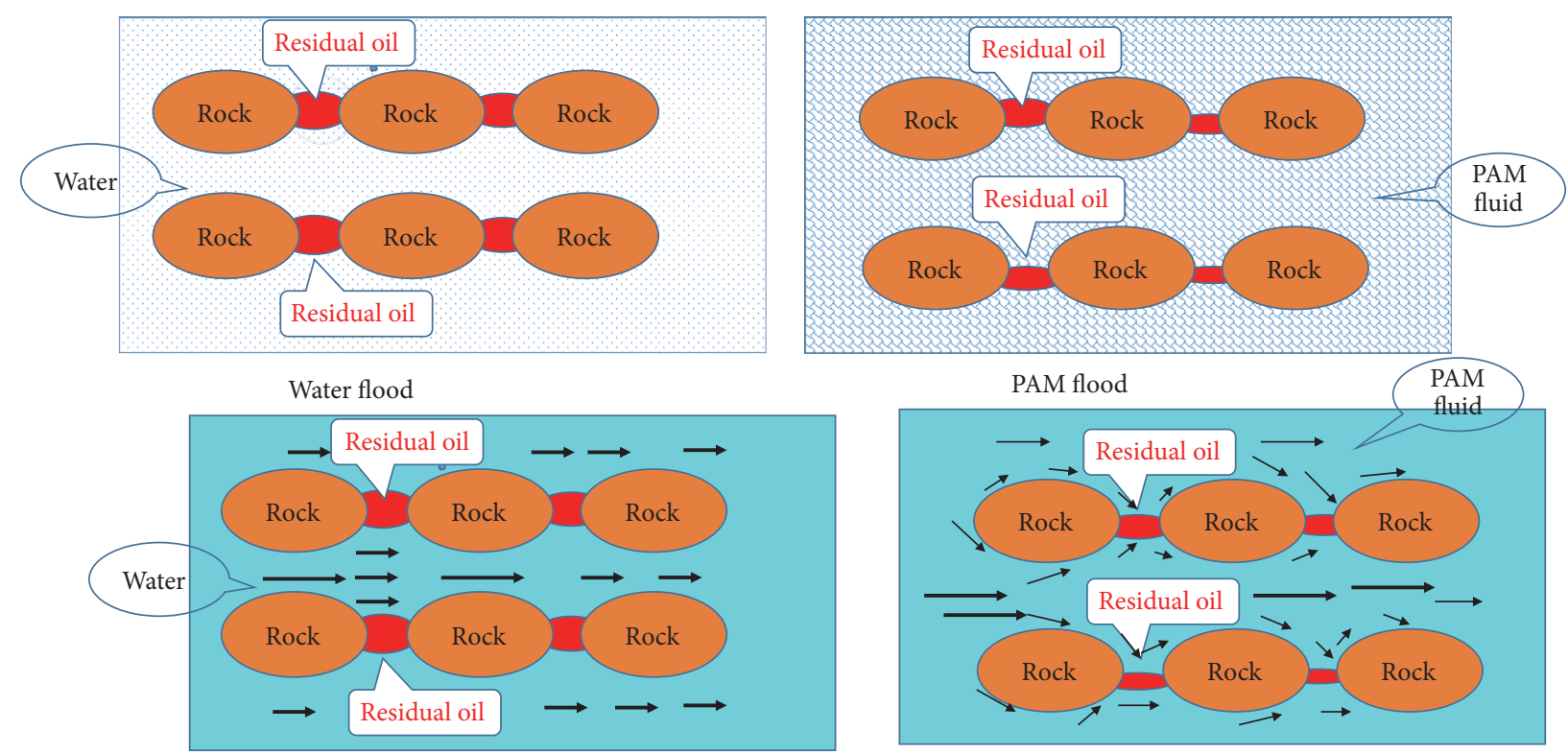

Water flood

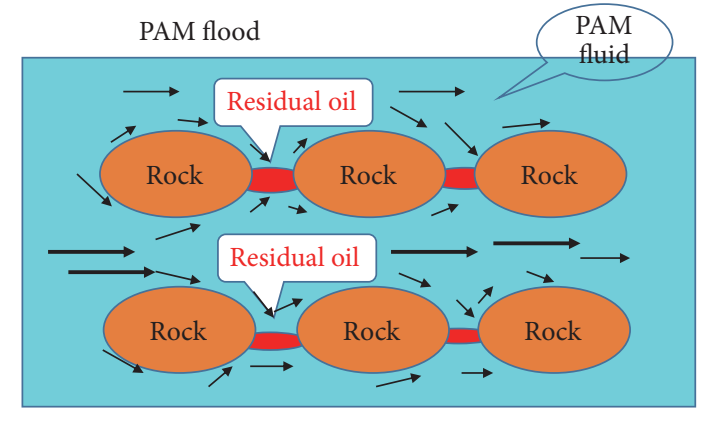

PAM flood

FIGURE 2: Influence of viscoelasticity on displacement efficiency [7].

Some studies have shown that ASP flooding can enhance oil recovery by $20 \%[5,37]$ while the test in Daqing oilfield shows that polymer flooding can enhance oil recovery by $10 \%$.

Though it is almost impossible to fully distinguish remaining oil and residual oil in core flooding tests because of heterogeneity, these two concepts are important in chemical EOR. Displacement efficiency is related to residual oil saturation, while sweep efficiency mainly involves remaining oil saturation. They have connections and differences. Not all swept areas cause displacement efficiency change. In water flooding, displacement efficiency will not change unless the interfacial tension is reduced or the velocity increases. Displacement efficiency is determined by capillary number, while sweep efficiency is affected by mobility control. It should be aware that there is viscosity factor in capillary number definition; thus both displacement efficiency and sweep efficiency can be affected by capillary number. The polymer cannot significantly change capillary number; thus it has little effect on residual oil saturation. Though in core flooding tests the residual oil saturation can be reduced by polymer, it is due to enlarging sweep efficiency because heterogeneity always exist. Thus, even some core flooding tests claimed that polymer could reduce residual oil saturation [7]; it did not exclude the effect of heterogeneity effect on remaining oil saturation. In homogeneous media, polymer cannot reduce residual oil saturation, as can be seen in Koh et al. [31]. Clarke et al. [16] demonstrate with multiphase corefloods that flexible high-molecular-weight (HPAM) polymer solutions reduce residual oil, whereas solutions showing less elasticity (xanthan) do not; however, their tests also did not exclude the sweep efficiency improvement contribution. Homogeneous cores should be used to investigate the polymer effect on residual oil saturation.
2.3. Surfactant and IFT. The main use of surfactants is to reduce the interfacial tension (IFT) significantly between ASP system and crude oil. According to the classical capillary number theory and capillary desaturation curve (CDC), the residual oil saturation can decrease sharply when the IFT dramatically reduced to a certain extent. Although the nonNewtonian fluid does not conform to the capillary number theory [34], it is still widely accepted that low IFT and high oil displacement efficiency are the main reasons contributing to that the advantage of ASP over polymer flooding effects. The main surfactants [38] used in ASP solution are petroleum sulfonate, petroleum carboxylate, and non-ionicanionic surfactant. The prominent advantage of petroleum sulfonate is its simple production process and low price. The biggest advantages of non-ionic-anionic surfactants are their strong salt resistance and less formation absorption loss but it tends to kill microbes in the formation. However, it can largely decrease the viscosity of heavy oil [38]. The compounding of surfactant can reduce IFT, such as the compounding of petroleum sulfonate and carboxylate [38] and the compounding of biological surfactants Rhamnolipid broth and normal surfactant [39]. IFT contrast between single surfactant and surfactants mixtures is very obvious and the mixture surfactants has much lower IFT and concentration to form lower IFT [40]. We can see that the mixture surfactant $\mathrm{Sa} / \mathrm{c}$ surface tension is much lower than single surfactant Sa or Sc. Surfactants mixture is good and cheap way to find low IFT surfactants required [40]. In field tests Henan, Shengli, and Xinjiang, the mixtures surfactants were used. Alkali addiction can reduce IFT, as can be seen from [41]. In [41], it is obvious the ASP system IFT is much lower than the single composition of ASP. Heavy alkyl benzene sulfonate (HABS) and petroleum sulfonate were employed as the main strong alkali and weak alkali surfactants in Daqing oilfield, 
respectively [42]. In other ASP field tests in China, petroleum sulphate was used.

Although dynamic IFT is more recognized by some scholars [43-45] the equilibrium IFT is chosen as the evaluation parameter in most oilfields in China when the ASP flooding is evaluated $[38,46]$. Through experiments, dynamic IFT was found to have a major impact on oil displacement [43]. Meanwhile, the correlation of the lowest value dynamic IFT and oil displacement efficiency was more obvious, while the IFT steady-state value was not so important [44]. A view [25] that unified dynamic IFT and equilibrium IFT showed a significant reduction in the minimum dynamic IFT during the ASP flooding time, and it could promote water flood residual oil to start to remobilize in a short time after the ASP system is in contact with oil. Meanwhile, the maintaining of a low equilibrium IFT can lead to the ASP system to continue to effectively erode blind and film type residual oil which was difficult to be displaced. The equilibrium IFT of 120 minutes is selected as IFT in Daqing. The main reason is that surfactant migration in formation is a long process and it requires time to get to the oil/water interface to remobilize residual oil saturation. At present, there is no consensus on this issue.

According to capillary number theory and classical CDC, the equilibrium IFT of ASP system was required to be as low as $10^{-2} \mathrm{mN} / \mathrm{m}$ even $10^{-3} \mathrm{mN} / \mathrm{m}$ orders of magnitude and it would be best if it has a wide range of surfactant concentration [13-15]. In addition to developing more efficient and cost-effective surfactants, factors affecting the IFT are also concerned $[13-15,47]$. The polymer concentration has little impact on the oil-water IFT, and the IFT of polymer with different concentrations is at the same order of magnitude. Alkali concentration is a controlling factor of the IFT, and only when the alkali concentration reaches a certain degree can it achieve ultralow IFT [47]. The acid value of crude oil is believed to be the key factor to affect the IFT of ASP flooding. It is easy to choose surfactants for the crude oil with its acid value larger than $0.2 \mathrm{mgKOH} / \mathrm{g}$; the crude oil with acid value less than $0.01 \mathrm{mgKOH} / \mathrm{g}$ is believed unsuitable for ASP flooding. The crude oil composition accounted for this low acid value. Low acid value Daqing oil composition in contrast with high acid value Shengli oil can be seen in [48]. The main difference is asphaltenes (paraffinic crude oil). The effect degree order of IFT reducing ability for group components by alkylbenzene sulfonate (ABS) surfactants was resins > aromatics $>$ saturates $>$ wax $[6,49]$. It is not easy for Daqing oil to form ultralow IFT with surfactant. However, practice in Daqing confirmed that low acid value oil was possible to be implement in ASP flooding. In addition to organic acids in crude oil, resin, and asphaltene were also found to be important factors in the formation of ultralow IFT. It was found through experiments that the active substance formed by nitrogen-containing heterocyclic compounds and alkali could produce synergistic effect with alkyl benzene sulfonate, reducing IFT. Such effect equals to that of acidic active component, solving the problems of low acid ASP flooding creatively in Daqing oilfield [13-15]. This progress is crucial for reservoirs that have low acid value crude. It is the cheap surfactant produced in China that makes it possible to carry out ASP flooding in industrial application. This conclusion

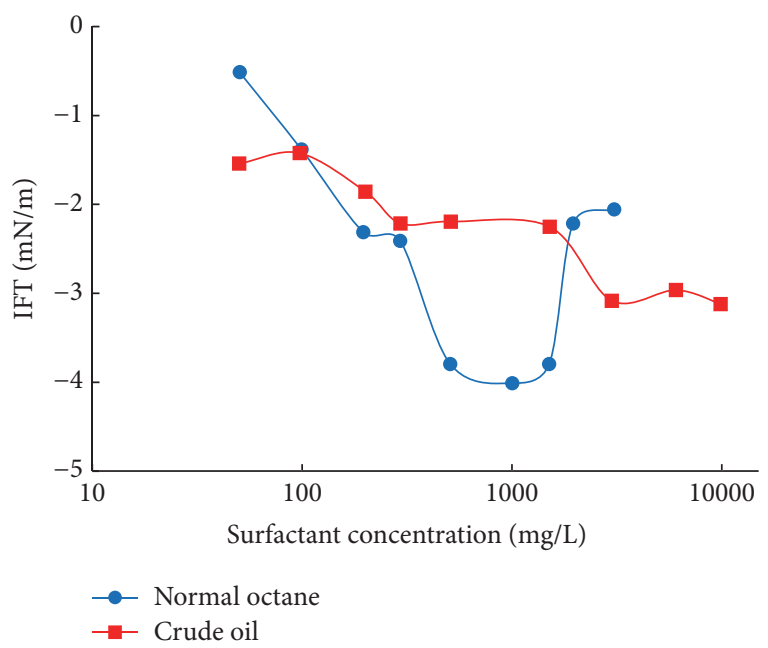

FIgURE 3: IFT between normal octane and crude oil [8].

is in line with other researchers [8]. The IFT performance between normal octane and crude oil in Henan can be seen in Figure 3 [8]. This difference in Figure 3 may be attributed to some lipophilic species partitioning into the oil, carboxylate changing from soap-type (-COONa) to acid-type (-COOH), and naphthenic acids interacting with surfactant according to Li et al. [8].

Cui et al. [50] studied the dynamic and equilibrium IFT properties of alkali/heavy alkyl benzene sulfonate (HABS)/Daqing crude. When alkali concentration varied in a certain range, the dynamic IFT of alkali/HABS/oil system exhibited obvious lowest phenomenon, and the lowest point of the dynamic IFT could reach $10^{-3}-10^{-5} \mathrm{mN} / \mathrm{m}$ order of magnitude, while the equilibrium IFT just reached $10^{-3} \mathrm{mN} / \mathrm{m}$ order of magnitude. Too low or too high alkali concentration would lead to high equilibrium IFT. Equilibrium IFT of alkali/surfactant/oil system was also related to the surfactant concentration. Zhu et al. [51] found that the sulfonated synthetic alkyl benzene sulfonate surfactant enabled the IFT of oil in Daqing and Dagang oilfield reach ultralow level at low alkali concentration, with the ranges of alkali concentration of ultralow IFT being, respectively, $0.5 \%$ and $0.6 \%$, and the surfactant concentrations being, respectively, $0.025 \%$ to $0.2 \%$ and $0.025 \%$ to $0.3 \%$. The synthesized surfactant system was preferably stable, which could still maintain ultralow IFT after 30 days. By using the ASP oil displacement agent remixed by synthesized surfactant, laboratory flooding experiments could enhance oil recovery by $20 \%$ more than that of water flooding.

It was later proposed by Jia et al. [25] that IFT can be divided into two stages, equilibrium IFT and dynamic IFT, after the ASP system contacted with the oil. ASP flooding can reduce the lowest dynamic IFT so as to help to displace the residual oil rapidly after water flooding. At the same time, maintaining a lower equilibrium IFT can make ASP solution effectively displace blind and membranous residual oil to obtain higher recovery factor. The recovery of ASP flooding increased at a larger degree if the IFT is lower. In order to enhance oil recovery of $20 \%$ by ASP flooding, the equilibrium 
IFT between ASP solution and crude oil must be reduced to $10^{-3} \mathrm{mN} / \mathrm{m}$. When equilibrium IFT is similar, reducing the lowest dynamic IFT drastically can enhance oil recovery significantly. This conclusion was accepted by engineers in Daqing and was regarded as one basic screening parameter.

According to typical capillary desaturation curve, as the IFT gets lower, the capillary number gets larger and the residual oil saturation goes lower which in turn enhance the oil displacement efficiency [18, 19] (Delshad et al. 1986), [2023]. When capillary number increase to critical value, the residual oil saturation can be reduced drastically. Therefore, based on capillary number theory and laboratory experiments, the IFT of chemical system and crude oil should be as low as $10^{-3} \mathrm{mN} / \mathrm{m}$ to achieve the EOR of $20 \%$ with ASP flooding [25]. However, this conclusion was argued by some researchers that lower IFT cannot necessarily guarantee the higher EOR, which means that the IFT does not have to be as low as $10^{-3} \mathrm{mN} / \mathrm{m}[45,47]$. Qi et al. [52, 53] gave new capillary desaturation curve (CDC) named QL curve with high capillary number through $1 \mathrm{D}$ and $2 \mathrm{D}$ laboratory core flooding experiments. The main distinctions between QL curve and typical classical CDC can be reflected in several aspects. There are three critical capillary number values, Ncc, Nct1, and Nct2. The relationship between residual oil and capillary number values varies with the change of capillary number. If the capillary number is less than close to critical capillary number Ncc, the residual oil saturation tends to be a constant. If the capillary number increases from Ncc to Nct2, the corresponding compound chemical flooding residual oil saturation reduces linearly. If capillary number increases further to Nctl, the residual oil saturation tends to be approximately constant again. When capillary number goes higher than Nctl, residual oil saturation is complex to present both trends of increase or decrease, which is interpreted as the transition in flooding conditions.

The experimental conditions of QL curve differing from that of CDC lie in the core, the shape of which is rectangular and the heterogeneity of which is taken into consideration. The so-called QL curve is actually different from typical CDC, which is based on short cylinder cores. Classic CDC seldom involves the remaining oil saturation, while in $2 \mathrm{D}$ model like Qi et al. [52, 53] used the remaining oil saturation as important factor. Though the curve may be not real CDC, if CDC is defined and got from short cylindrical core, QL curve is still valuable in ASP flooding. The capillary number should be controlled within reasonable range by proper designing, especially the relationship between increase sweep volume and reduce IFT. Though the results concluded with this new proposed QL curve have not been verified widely by other researchers, what is worth noting is that similar conclusions with experiments have been put forward that the ultralow IFT cannot necessarily guarantee high enhanced oil recovery. During examining the effect of IFT on ASP flooding, Li et al. [45] proposed that the IFT does not have to be required to be $10^{-3} \mathrm{mN} / \mathrm{m}$ to obtain the EOR of $20 \%$ and that the dominating factor of the oil displacement efficiency is the lowest value of instant dynamic oil-water IFT instead of balance IFT. Interfacial tension of $10^{-2} \mathrm{mN} / \mathrm{m}$ may be low enough to reach a high incremental oil recovery factor [5]. Results from experiments show that under the conditions of Daqing oilfield, the lowest dynamic oil-water IFT can be as low as $10^{-2} \mathrm{mN} / \mathrm{m}$ though balance IFT is only $10^{-1} \mathrm{mN} / \mathrm{m}$, while the oil displacement efficiency is almost the same as that with balance IFT of $10^{-3} \mathrm{mN} / \mathrm{m}$. Besides, compared with the condition in which alkaline is present and balance IFT reaches $10^{-3} \mathrm{mN} / \mathrm{m}$, the oil displacement efficiency is roughly the same as that under the condition in which the alkaline is absent while the dynamic oil-water IFT reaches $10^{-2} \mathrm{mN} / \mathrm{m}$. The application condition analysis of ASP with low concentration of alkaline also shows that the same oil displacement efficiency with ultralow IFT can be achieved by adjusting the system viscosity even though the IFT cannot be as low as $10^{-3} \mathrm{mN} / \mathrm{m}$. That compound chemical system reaching ultralow IFT is not the absolutely necessary conditions of ASP application [47]. A noteworthy field trial proved that lower IFT cannot definitely guarantee a higher oil displacement efficiency. The data from sealing coring of water flooding and ASP flooding inspection wells which are merely 50 meters away show that the oil displacement efficiency with ASP in West Xing'er (X-2-X) is the same as that with water flooding. In other words, ultralow IFT cannot definitely guarantee a greater oil displacement efficiency. As to the mechanisms of this phenomenon, further work needs to be done.

Besides decreasing the IFT, surfactant in ASP flooding can change the wettability effectively. Wettability of a reservoir rock has a dominant effect on interface movement and associated displacement of oil through porous media. Changes of wettability, often reflected by contact angle change, from oil-wet to water-wet increase the oil recovery significantly [4]. Kumar and Mandal [4] studied three different types of surfactants effect on contact angle change in and without presence of alkali. All tested three surfactants can reduce contact angle to a lower value within a very small period of time. The contact angle values are further decreased in presence of alkali resulting conversion of intermediate wet quartz to water-wet, which is the preferential need for the enhanced oil recovery [4]. The ASP flooding can alter the reservoir rock wettability from oil-wet to water-wet, as verified by coring before and after ASP flooding field test [1315]. This helped explain why ASP flooding can improve both sweep efficiency and displacement efficiency.

2.4. Alkali and Corrosion. In ASP flooding, the main purpose of adding alkali is to use cheap alkali to replace expensive surfactants so as to achieve its goal of reducing the IFT [1315]. Alkali can reduce adsorption of the surfactant [5] and also adsorption of polymer because alkali reduces surfactant adsorption by increasing the rock surface's negative charge density, making it preferentially water-wet [24]. Surfactant and polymer adsorption can be reduced by raising $\mathrm{pH}$ with alkali [10]. The authors revealed that the surfactant adsorption was reduced by $49 \%$ when the $\mathrm{pH}$ of the permeating fluid was increased from 6.3 to 10.2 [54]. Surfactant adsorption experiments showed that ammonia was able to reduce the 


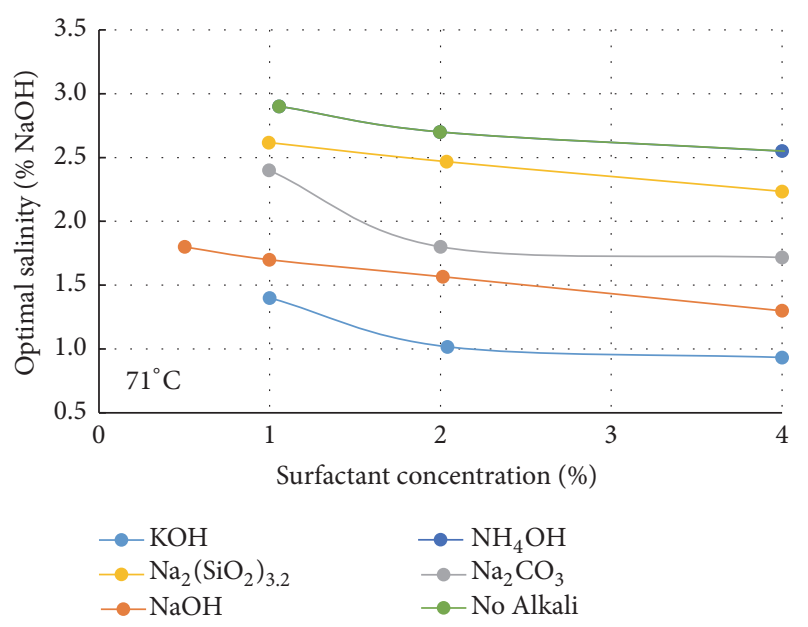

FIGURE 4: Influence of combined cation content on optimal for $1 \% \mathrm{wt}$ alkali chemical, brine, n-tetra decane, and surfactant [9].

adsorption on sandstones, but not much difference was observed for carbonates [55]. The use of alkali in a chemical flood offers several benefits including promoting crude oil emulsification, increasing aqueous-phase ionic strength leading to regulation of phase behavior of the injected surfactant, and lowering interfacial tension (IFT) to ultralow values in presence of surfactant [24]. Tests have shown that the presence of any alkali lowers the optimal salinity for surfactant, as can be seen from Figure 4 [9]. Alkali also reacts with the acids in the crude oils to produce in situ soaps, which in turn broadens the optimal salinity range [24]. As for low acid value Daqing oil, it is not the case. Results indicated that surfactant did not produce ultralow water-oil IFT values. However, the addition of $1 \mathrm{wt} . \% \mathrm{NaOH}$ enabled them to reach this condition [10]. In early ASP flooding research in Daqing, $\mathrm{NaOH}$ is selected because of its high $\mathrm{pH}$ value. High $\mathrm{pH}$ value has benefit of alkali flooding [56]. Detailed alkali crude oil reaction can be seen in [56]. It also helps to form ultralow IFT between low acid value Daqing oil and surfactant (ORS41). High $\mathrm{pH}$ value is also believed helpful to emulsification. The $\mathrm{pH}$ value of different alkali can be seen from [57]. Alkali has a relatively large impact on the polymer [13-15], (Tang et al. 2003). A high alkaline concentration will also reduce polymer viscosity; thus more polymer will be needed to reach a required viscosity [5]. Viscosity reduction effect by alkali and viscosity stability between polymer, surfactantpolymer, and alkali-surfactant-polymer can be seen in [8]. In addition, alkali can change wettability $[1,4,25]$. The presence of alkali can alter formation wettability to reach either more water-wet or more oil-wet states [24]. Kumar and Mandal [4] studied wettability change by testing contact angel and found that alkali and surfactant can change rock wettability from intermediate wet to completely water-wet. Changes of wettability from oil-wet to water-wet increases the oil recovery significantly [4]. The wettability alteration function of alkali is reflected by the chemical reaction among alkali, rocks, and clay minerals in the reservoir. Through ion exchange, the original clay minerals change into more hydrated sodium type clay, thus to alter wettability from oilwet to water-wet [25]. The most important two functions of alkali in ASP are to reduce IFT and surfactant adsorption. IFT difference between SP and ASP is quite distinct $[8,58]$. In ASP flooding, IFT is one of the most important parameters, if not the most important. However, there are also side effects such as corrosion and scaling handling difficulties in emulsified liquid treatment. Strong alkali ASP flooding should be replaced by weak base ASP flooding, even by alkali-polymer flooding [37, 59]. New surfactant that makes emulsion easy to breakthrough is under development [42]. As for the function of alkali, previous study focused more on viscosity damage of alkali to ASP system, the impact of alkali on the IFT, alkali corrosion-scaling, and the measures of preventing scaling. Recently, more focus is given on weak alkali $\left(\mathrm{Na}_{2} \mathrm{CO}_{3}\right)$ and most new ASP flooding field tests in China outside Daqing is $\mathrm{Na}_{2} \mathrm{CO}_{3}$ based.

Alkali also causes the loss of polymer viscosity. Viscosity difference between polymer, SP, and ASP can be seen in [8]. Different from other surfactant that has no significant influence on polymer viscosity, the surfactant $\mathrm{Sa} / \mathrm{c}$ has increased polymer viscosity obviously. The surfactant $\mathrm{Sa} / \mathrm{c}$ is mixtures of anionic/Cationic Surfactants. The surfactants is using in $80^{\circ} \mathrm{C}$ reservoir ASP flooding field tests in Henan oilfield. Experiment in Daqing showed that viscosity was largely reduced by addition of alkali [60]. Alkali can reduce polymer viscosity seriously, depending on polymer concentration, molecular weight, and alkali type [60]. $\mathrm{NaOH}$ could reduce polymer viscosity by $41 \%$ (polymer concentration $1800 \mathrm{ppm}$ ) [60]. The higher alkali concentration, the lower ASP viscosity. Thus, to get the adequate viscosity, the polymer concentration or molecular weight should be increased, which in turn increased cost. Xia et al. [47] found that reasonable alkali concentration should consider both reservoir heterogeneity and reservoir homogeneity. For a homogeneous core, the change of the interfacial activity of the composite system has a greater impact on the recovery system than that of viscosity and viscoelasticity. For heterogeneous core, higher alkaline and lower IFT system have a limited effect on oil displacement. The viscosity and viscoelasticity of high alkaline system are vulnerable. Later, Hou et al. [60] found that there existed a minimum viscosity value of ASP solution for ultralow IFT systems to fully work towards improving residual oil recovery. This minimum viscosity is defined as critical displacement viscosity. When the viscosity of an ASP solution is lower than the critical displacement viscosity, the oil recovery efficiency of ASP flooding is dominated by the viscosity of the ASP solution. The reduction in interfacial tension to an ultralow level contributed little to oil recovery. When the viscosity is higher than the critical displacement viscosity, both viscosity and ultralow IFT contributed to oil recovery.

The alkali selection is not an easy matter. Alkali studied for ASP flooding includes organic and inorganic alkali $[5,24,58,61]$. IFT between organic and inorganic for a high temperature $\left(80^{\circ} \mathrm{C}\right)$ [58] indicated that for ultrahigh temperature reservoir, inorganic alkali may be a good choice. In laboratory, all alkali was investigated and sodium carbonate $\left(\mathrm{Na}_{2} \mathrm{CO}_{3}\right)$ drew most attention and was used in the 
majority of field tests $[5,24]$. Sodium hydroxide $(\mathrm{NaOH})$ was frequently used in many ASP field tests. Metaborate $\left(\mathrm{NaBO}_{2}\right)$ and ammonium hydroxide $\left(\mathrm{NH}_{4} \mathrm{OH}\right)$ may be used as alkalis in such cases as they are shown to tolerate gypsum which is commonly encountered in carbonate reservoirs [61]. As for ultrahigh temperature reservoir, inorganic alkali like cholamine may be a good choice in ASP flooding [58]. Recently, there are increasing interests of using ammonium hydroxide as alkali in offshore ASP flooding [55, 61]. In China, both $\mathrm{NaOH}$ and $\mathrm{Na}_{2} \mathrm{CO}_{3}$ are used in large scale field tests in Daqing and also industrial application [59]. Other field tests in China all used $\mathrm{Na}_{2} \mathrm{CO}_{3}$. For many engineers, it is surprising that $\mathrm{NaOH}$ was used in the majority of field tests in Daqing. In fact, from 2007 to 2009, 4 enlarged commercial application and demonstration ASP flooding blocks with nearly 1000 wells in Daqing were all $\mathrm{NaOH}$ based [59]. In early ASP field tests in Daqing, limited surfactants can be found to form ultralow IFT between low acid value Daqing oil. Surfactant screened can form ultralow IFT in presence of $\mathrm{NaOH}$ [10]. It is mainly surfactant IFT requirement that determined the $\mathrm{NaOH}$ employment in many Daqing field tests. Daqing oilfield has spent tremendous energy to overcome the disadvantages caused by $\mathrm{NaOH}$ and has got great achievements in antiscaling [13-15]. In previous ASP flooding tests in Daqing, heavy alkyl benzene sulfonate (HABS) and petroleum sulfonate were employed as the main strong alkali and weak alkali surfactants, respectively [42]. The drastic decrease in oil price makes engineers reevaluate $\mathrm{NaOH}$ based ASP flooding and emphasize economic evaluation more than ever. There is more and more interest on weak alkali ASP flooding in Daqing [37, 59], and the feasibility of strong alkali surfactant heavy alkyl benzene sulphonate (HABS) used with $\mathrm{Na}_{2} \mathrm{CO}_{3}$ was investigated [57]. The progress in surfactant production makes it possible to produce large amount and cheap surfactant used for weak alkali ASP flooding. Comparison between two finished large scale ASP flooding field tests performances was finished in 2016 [62] and it is obvious that weak alkali is better choice. Mechanism between $\mathrm{NaOH}$ and $\mathrm{Na}_{2} \mathrm{CO}_{3}$ ASP flooding in laboratory is thus interesting to many engineers and researchers. Figure 5 [10] showed the IFT performances between $\mathrm{NaOH}$ and $\mathrm{Na}_{2} \mathrm{CO}_{3}$ under the same condition. In these experiment, IFT from $\mathrm{NaOH}$ is lower than that from $\mathrm{Na}_{2} \mathrm{CO}_{3}$ for high acid value oil. The oil tested here has much higher acid value compared to Daqing oil. Other research also indicates that $\mathrm{NaOH}$ appears to be slightly more effective in reducing IFT than $\mathrm{Na}_{2} \mathrm{CO}_{3}$ [63].

Alkali corrosion restricted the application of ASP flooding, while the universal concern is focused on how to prevent or weaken corrosion. Corrosion and scaling in strong alkali ASP flooding are worse than that in weak alkali ASP flooding [62]. The scaling mechanism and scaling type of strong alkali and weak alkali were briefly compared [62]. In weak alkali ASP flooding, scaling samples are mainly carbonate scale, while scale in strong alkali ASP flooding is carbonate scale and silica scale. As $\mathrm{PH}$ increases, silica scale percentage increases. At some stage, silica scale percentage is up to $60 \%$ in strong alkali ASP flooding, while in weak alkali scale it is less than $5 \%$. The use of weak alkali or nonalkali flooding is the development direction [37]. X.-J. Wang and Q.-G. Wang

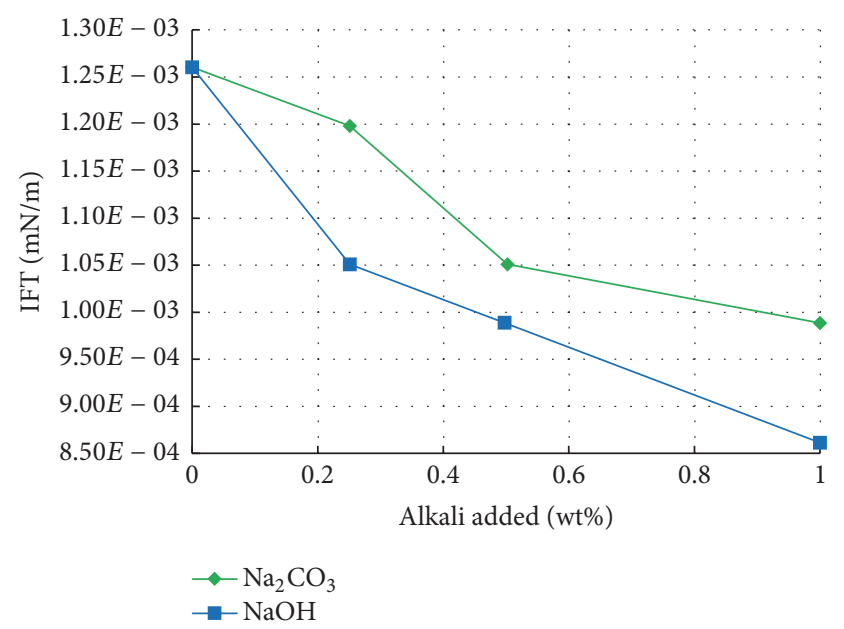

FIGURE 5: IFT versus alkali weight fraction and type [10].

[64] analyzed the main components and types of well scaling based on the data of two production wells in Daqing oilfield ASP flooding test area and concluded that the scale is mainly aluminum scale and silicate scale. Further studies showed that [64] there are chemical elements scale, such as silicon, aluminum, calcium, iron, sodium, barium, and compounds scale like $\mathrm{SiO}_{2}(67.7 \% \sim 71.4 \%), \mathrm{Al}_{2} \mathrm{O}_{3}$ (3.49\% 5.56\%), $\mathrm{CaO}$ (6.22\% 9.04\%), $\mathrm{Fe}_{2} \mathrm{O}_{3}$ ( 2.45\%), and $\mathrm{BaO}(2.0 \% \sim 12.0 \%)$, with the total amount of compound scale making up more than $80 \%$ of the total amount. In order to solve the scaling problem in Daqing oilfield, clear detergents are developed which are composed of the composite acid, scale transformation, chelating agents, surfactants, release agents, and water. Laboratory experiments show that the scale dissolved by clear detergents can be larger than $80 \%$ in each block well in Daqing field at $45^{\circ} \mathrm{C}$. Li et al. $[46,65,66]$ regarded the alkali as the key factors to dissolute the reservoir rock to generate silica scale. Alkali leads to the different scale of increase of permeability and porosity in sandstone reservoirs; high formation temperature exacerbated the dissolution of the reservoir rock, and the pressure had no significant effect. When the fluid with rich Si4+ migrates into the wellbore and ground systems, the soluble sandstone detritus will reach the saturation point and precipitate out as the temperature increases. After years of hard work, the scaling problem in ASP flooding has been solved. Physical method together with chemical method was used in all ASP tests, although different measures were used according to scaling stages [1315]. According to latest data from Daqing, Carbonate scale removal rate can be $95 \%$ while silica scale removal rate is below $80 \%$. Producer pump-checking rate can be extended from previous about 30 days, 100 days to 383 days, and 467 days for strong alkali and weak alkali, respectively.

2.5. Emulsification. The phenomenon of emulsification in ASP flooding is obvious. It is studied by many scholars [13$15,25,26,46,65-67]$. Emulsification is believed as one of the main mechanism of ASP flooding [13-15, 25, 26]. Many ASP flooding field tests indicated that all high incremental 


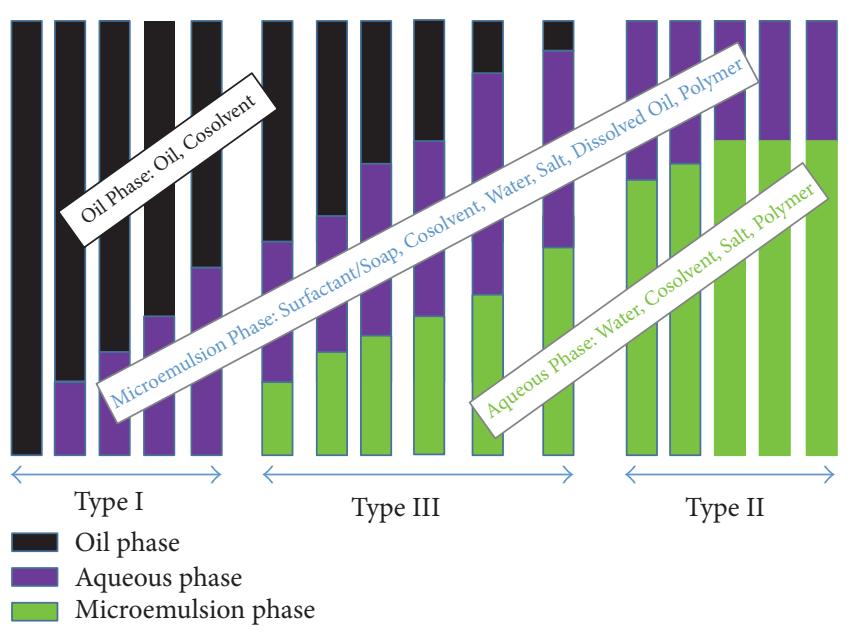

FIGURE 6: Effect of salinity on phase behavior [11].

oil recovery or good performance wells were seen strong emulsification, while poor performances wells were seen no or little emulsification. Field tests also showed that emulsion stability affected the recovery [13-15]. ASP flooding in Xinjiang indicated that the recovery performance is good if the emulsification capacity of surfactant is good, even its IFT is cannot reach $10^{-3} \mathrm{mN} / \mathrm{m}$, and the recovery performance is bad for poor emulsification capacity surfactant, even it can reach ultralow IFT [42]. As for the specific mechanism of emulsification and emulsion's contribution to the recovery degree $[13-15,25,46,65,66]$, though many researchers are very interested, the mechanism is still unclear. Recent research shows that [13-15], the contribution of emulsifying ability of ASP system to oil displacement efficiency can be as high as $30 \%$ [13-15], although there are still metering problems during experiment.

It is well accepted that salinity and oil content have important effect on emulsion type $[4,11,68]$. As salinity increase, emulsion type changes from Winsor Type I, Type III, and Type II, as can be seen from Figure 6 [11]. In Type III, the middle phase is microemulsion where optimum salinity is determined. Phase behavior changes with increase of salinity and alkali concentration is well studied in [10]. Kumar and Mandal [4] compared different type surfactants (cationic, anionic, and nonionic) effect on emulsion drop size and number and stability in presence of alkali and optimum salinity. Their study shows that alkali promotes the emulsification process and its stability which leads to formation of tight emulsions. The microscopic images of different emulsions are shown in Figure 7 [12], and microscopic images of emulsion formed by different surfactants and alkalis may be seen from literature [4]. Since the optimum salinity is often too high for low salinity formation like Daqing oilfield, researchers in China are interested in other factors like properties of oil and water, type and concentration of chemical, water cut and external force, pore structure, permeability, and viscosity $[25,46,65,66]$. The emulsifying ability of strong alkali is better than weak alkali [10].
There is no widely accepted method to characterize emulsifying performance, especially for the quantitative characterization. The main problem is emulsifying simulation equipment and quantitative evaluation index of emulsifying ability. The biggest drawback of conventional method is that it is unable to simulate the porous medium. The common drawback of current emulsification characterization method is unable to quantitatively characterize the influencing factors of emulsion. How to develop an experimental equipment to simulate the emulsion in porous media and quantitatively characterize and evaluate emulsifying ability of chemical system is the problem needing to be solved.

The ASP fluid demulsification is difficult. Emulsion from weak alkali ASP flooding is much easier to break and dehydrate than that from strong alkali ASP flooding [62]. Bituminous and gelatin content increase the difficulty of dehydration of oil emulsification and the influence of asphalt is greater than the colloid [67]. The main stability mechanism of produced liquid of ASP flooding is different from that of polymer flooding, due to supersaturated stability mechanism and space steric stabilization mechanism [13-15]. This was revealed through the research of fluid composition, microstructure, properties, and the property of oil-water interface, the laboratory experiment medium in Daqing oilfield [13-15]. They have developed a series of SP demulsifier and WS water quality stabilizer to solve the problem of oil and water efficient separation in produced liquid efficiently. Except for using weak alkali ASP flooding, switchable surfactant for ASP flooding may be a good way to solve the emulsion breaking problem [42].

2.6. Applicability and Slug Combination. The reservoir selection criteria of ASP flooding include the density, viscosity of crude oil, crude oil composition, original oil saturation, reservoir depth, and temperature [69]. The application range of ASP flooding is wide [70]. Except the low permeability reservoir, the conventional oil and heavy oil reservoir can be found in the literature, according to Li [71] and Zhang et al. [72]. The focus of research has changed from the Class I reservoirs which have good reservoir condition to the Class II reservoirs which have worse reservoir condition according to CNPC standard [13-15].

Evaluation in laboratory focuses on optimization of the each composition amount, slug size, and injection timing. For the detailed technical route, according to the specific reservoir conditions, the viscosity range of flooding system can be determined based on mobility control. Secondly, Polymer's molecular weight and concentration are selected. Thirdly, the concentration of surfactant and alkali are selected. Incremental oil recovery is the selection standard of flooding system optimization to determine IFT and viscosity. Laboratory study of oil displacement system mainly focuses on the mutual interactions, compatibility and displacement characteristics of alkali, surfactant, and polymer. When optimizing the slug, heterogeneity, and slug combination, technical problems are also taken into consideration. The selected slug size is $0.3 \mathrm{PV}$ mostly [73], and 0.35 PV [73-76]. At present, the size of slug is generally greater than $0.30 \mathrm{PV}$ in the actual field tests and the highest value of it can achieve 


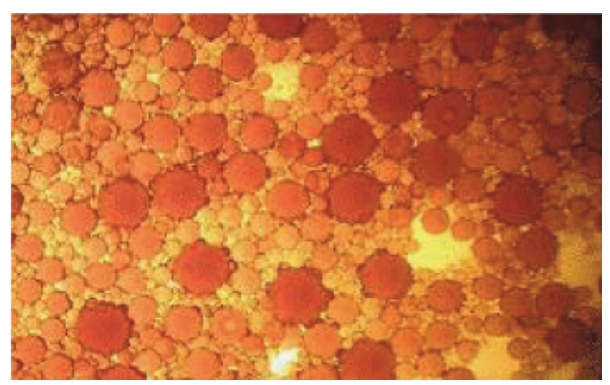

(a)

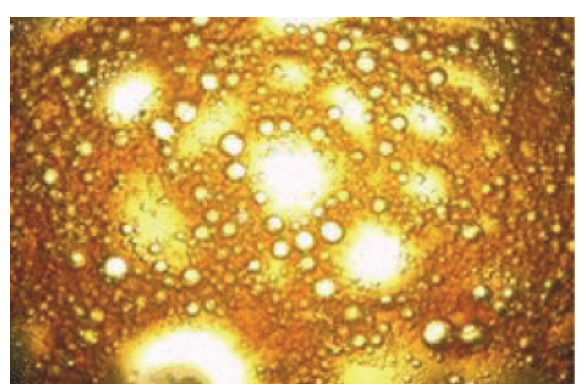

(b)

FIgURE 7: Microscopic views of the (a) water-external emulsion and (b) oil-external emulsion, [12].

0.50 PV. The average size of preslug is $0.097 \mathrm{PV}$. The average size of followed slug is $0.097 \mathrm{PV}[5,73,77]$. The reservoir heterogeneity, permeability differential, rock mineral adsorption, and formation fluid dilution effect have been taken into consideration in Daqing oilfield [13-15]. Considering physical and numerical simulation and contrasting with the improved recovery effect, the average slug combination had been determined as 0.04 PV prepolymer slug + 0.30 PV main slug $+0.15 \mathrm{PV}$ vice slug $+0.20 \mathrm{PV}$ postpolymer slug. The alkali concentration and surfactant concentration in main slug were $1.2 \%$ and $0.3 \%$, respectively, and they were $1 \%$ and $0.1 \%$, respectively, in vice slug.

In addition to the study of ASP flooding in high permeability and thin oil reservoir, the laboratory research of ASP flooding in low permeability reservoirs has been also carried out. Zhang et al. [72] had selected the system of ASP for low permeability reservoir in Honggang oilfield. The formulation can realize ultralow IFT under the condition of reservoir and can increase oil recovery after water flooding by $10 \%$ OOIP based on water flooding in the experiment. Li [71] lowered permeability limit to apply ASP flooding to $16.2 \mathrm{mD}$, lower than the value $50 \mathrm{mD}$ proposed by Sheng [5].

The majority ASP flooding is in light oil reservoir like Daqing; some ASP flooding is used in heavy oil reservoir in the domestic and overseas [77, 78]. Pei (2010) compared mechanism of ASP flooding and foam flooding of heavy oil by the oil displacement experiments using microscopic model and found that, for heavy oil, the ability to improve the sweep efficiency of ASP is limited compared to foam polymer. Jiang et al. [78] studied the influence factors of chemical flooding of heavy oil. He thought that, for heavy oil reservoir, oil recovery and IFT have no corresponding relationship and IFT is not the main factor to influence the recovery. High IFT can also obtain high recovery. His studies indicate that improving the sweep efficiency is the key to improving recovery in viscous oil.

2.7. Adsorption and Chromatographic Separation. ASP have three components, polymer, alkali, and surfactant, and these components may affect each other. At present, research has focused on the following aspects in China: (1) the comparison between water flooding and ASP flooding, polymer flooding $[67,79,80],(2)$ micromechanism of enhancing oil displacement efficiency of ASP [81, 82], (3) the interaction between components of ASP and formation fluid, as well as formation mineral [67, 74-76], (4) the synergy between various components of ASP flooding [13-15, 83].

The mechanism of synergy of ASP flooding has always been given attention. ASP flooding owes its success to the synergy of the individual components of enhanced oil recovery (EOR) blends [24]. An important mechanism is the synergy between in situ generated soap and synthetic surfactant. An explanation from the perspective of IFT is that surface active substance formed by alkali and acid of crude oil has an effect with applied surfactant to reduce oil-water IFT [13-15]. Generally, the optimum salinity for the soap is unrealistically low, and the optimum salinity for the surfactant is high. When they function together, the salinity range in which IFT reaches its low values is increased [24]. Sheng [5] concluded that injected alkali reduced the adsorption of surfactants and reacted with crude oil to produce the soap with emulsion to improve the sweep efficiency. Though acid value of Daqing oil is very low, reaction of $\mathrm{NaOH}$ with crude could reduce IFT to ultralow in 60 days (Shi, 2011). His experiment also indicates that $\mathrm{NaOH}$ could reduce oil viscosity and wax and pectin content. The competition of adsorption between polymer and surfactant will improve the sweep efficiency of alkali and surfactant. The combination of alkali, surfactants, and polymers leads to synergistic effects between the chemicals resulting in less surfactant required to recover significantly incremental oil.

Difference between ASP flooding, water flooding, and polymer flooding was investigated to reveal ASP flooding mechanism. Compared with water flooding, polymer flooding and ASP flooding can improve sweep efficiency. ASP flooding can greatly reduce the IFT, and thus can improve oil displacement efficiency. However it seems that polymer flooding cannot improve oil displacement efficiency significantly. Some scholars think viscoelastic polymer can enhance the microcosmic oil displacement efficiency by pulling effect [13-15], (Zhao et al. 2001), [34], but this contribution to displacement efficiency may be very small. The experience of Daqing oilfield shows that ASP flooding can improve recovery $20 \%$ based on water flooding, more than $10 \%$ based on polymer flooding [13-15]. During ASP slug screening, core flooding tests have to be done [3]. Because core flooding tests 
were finished on different physical models, like core plugs, sand packs, or artificial cores, the incremental oil recovery factor after water flooding is comparative within a certain range, depending on the similarity of tests scheme. Thus, in different literatures, the incremental oil recovery varies. In China, the minimum incremental oil recovery factor after water flooding should be more than $20 \%$, since the field tests showed that ASP flooding can enhance oil recovery $20 \%$ after water flooding.

Zhang et al. [67] have compared the differences between ASP flooding, polymer flooding, and water flooding by checking differences between produced fluid's composition. The contents of pectin, asphaltene, and aromatics are different between ASP flooding, polymer flooding, and water flooding, which are attributed to the interactions of pectin, asphaltene, and aromatics with different rock and the displacement ability of injected fluid. Wettability change in ASP flooding due to surfactant and alkali effects $[3,4]$ also results in decrease in asphaltene and pectin on rock surface.

Shen et al. [79] studied the heterogeneity and the influence of reservoir thickness on ASP flooding. According to their studies, the differences of permeability and reservoir thickness is the important factors influencing the chemical flooding effect. If heterogeneity of reservoir is not serious, improving the displacement efficiency is the key to improve the overall oil recovery of ASP. If heterogeneity of reservoir is serious, it should try to improve the sweep efficiency. The high permeable layer thickness accounted for the proportion of total thickness having a larger influence on ASP flooding. Due to interlayer adjustment function of polymer flooding, the change of the thickness has a small effect on oil displacement of polymer flooding. These studies indicated that the role of increase displacement efficiency and sweep efficiency may be different and reservoir heterogeneity should be given much attention.

Adsorption and retention of the surfactant are important issues affecting the effects of ASP flooding. Adsorption is an important index to select ASP surfactant. Daqing oilfield [13-15] required that if the static adsorption of surfactants on core $\leq 1 \mathrm{mg} /$ (g. sand) or less sand, dynamic acuities $\leq$ $0.1 \mathrm{mg} /$ (g. sand), the incremental oil recovery should be over $20 \%$. Surfactants used in China used to be imported product like B-100, ORS series. For cost consideration, all surfactants used are now produced in China. The surfactants can be seen in [5].

Li et al. [74-76] had studied the problems adsorption retention of each components of ASP flooding through laboratory simulation. Due to the competition of adsorption of polymer, the consumption of alkali is less than a single component. The main factors influencing the polymer adsorption are the $\mathrm{PH}$ value and salinity. The increasing of $\mathrm{PH}$ value and salinity will cause adsorption content increase. The value of adsorption of surfactant is most, followed by alkali and polymer. Using sacrificial agent, engineers can effectively reduce the loss of surfactant, but with little effect on polymer and alkali. Commonly used sacrificial agents are lignin sulfonate, silicate, organic phosphate, and sodium phosphate series.

\section{Field Tests}

Field test is an important necessary stage to make ASP flooding go from laboratory to application. The field test is generally based on experiments, through numerical simulation, in order to choose the suitable injection system, the injection mode, and pattern well spacing. According to the statistics of [5], among world's current finished 32 pilot test and industrial application, 19 were in China, 7 in the America, 3 in Canada, and 2 in India. In 2012, ASP flooding field tests in high temperature $\left(80^{\circ} \mathrm{C}\right)$ reservoir were implemented in Sinopec Henan oilfield and the stage incremental oil recovery at present is $7.7 \%$. The predicted incremental oil recovery is $14.6 \%$ and the total reservoir was $67.5 \%$ (Li et al., 2016). In 2015, the total product from ASP flooding is 3.5 million and the total oil production in Daqing in 2015 is 38.2 million ton. In 2016, there are 22 ASP flooding industrial blocks in Daqing, covering 7231 injectors and producer, in which 3 are new blocks. Considering the drastic decrease of oil price, any ASP flooding progress in Daqing will encourage oil industry participants.

Different from laboratory research, field test needs to consider and resolve the practical problems in production, such as corrosion and produced fluid treatment, which laboratory tests will not encounter. The average injection concentrations of these chemicals were $1.25 \mathrm{wt} \% \mathrm{~A}, 0.27 \mathrm{wt} \% \mathrm{~S}$, and $0.135 \mathrm{wt} \%$ $\mathrm{P}$, respectively, and $30.8 \% \mathrm{PV}$ was injected. The average incremental recovery factor and average water cut decrease were $21.8 \%$ original oil in place (OOIP) and $18 \%$, respectively. Since 1960 , field practice operation encountered many problems [70], such as low injectivity, polymer degradation, separating produced water from oil, pump failures, incomplete polymer dissolution, bacterial growth, corrosion, scaling, logistics, and handling. After years of work, Daqing oilfield has solved the key technical problems controlling ASP flooding [13-15]. The main controlling factors of key issues include ultralow IFT for low acid value of crude oil and formulation of ASP, surfactant localization and industrialization, antiscaling and lifting process design, and produced fluid disposal.

ASP flooding development scheme is based on laboratory studies [13-15].The overall design principle of Daqing oilfield is to enhance oil recovery and improve economic performance. Thus the design involves how to make the optimization of well spacing for maintaining a reasonable injection production ability and higher reserves control degree, to make the optimization of the combination of layers for decreasing the interference between layers and to select the optimal injection parameters for achieving efficient oil displacement effect and maximum economic benefits. In order to guarantee a certain injection and production capacity and the degree of control, with consideration of laboratory research and previous tests, well spacing is determined as $100-150$ meters, and control degree is greater than $70 \%$ [1315]. This screening process can be seen in Figures 8 and 9. Five-point well pattern is used in almost all field tests in Daqing. To determine the system of layer's combined thickness, it is necessary to consider the recovery increase and ensure a certain scale of production and economic benefits at the same time. When a barrel of oil is at $\$ 40$, the effective 


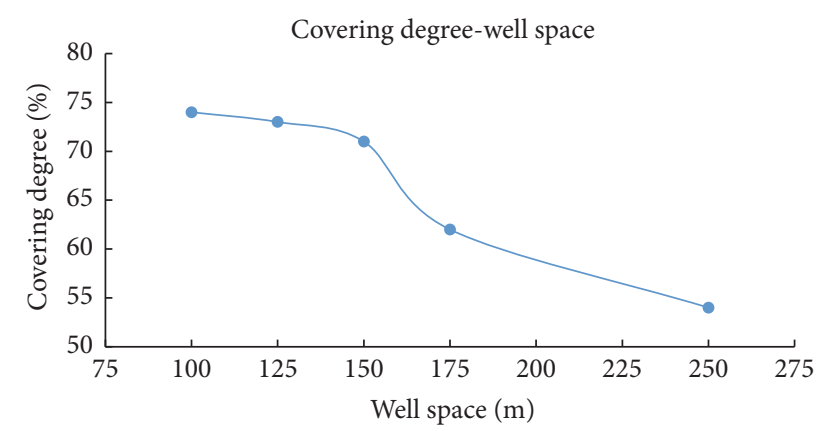

FIGURE 8: Relationship between injection production well space and covering degree [13-15].

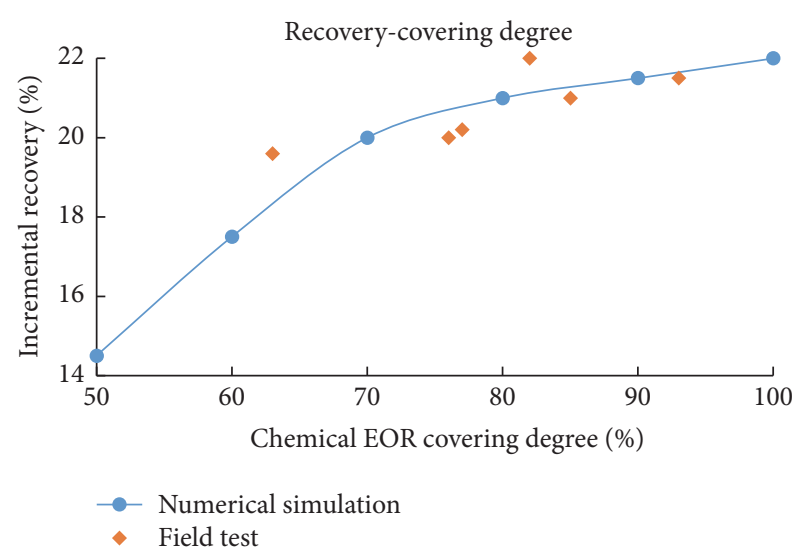

FIGURE 9: Relationship between covering degree and enhanced oil recovery factor [13-15].

thickness of layers is greater than $6 \mathrm{~m}$. Study on numerical simulation and field test shows that when the permeability range is less than 2.5 the value of recovery efficiency of ASP will be greater than $20 \%$. The optimization design of strong alkali ASP in B-1-DD is very typical in Daqing. The optimized slug includes $0.04 \mathrm{PV}$ prepolymer slug + 0.30 PV ASP slug + 0.15 PV ASP vice slug + 0.20 PV polymer slug. The concentrations of alkali and surfactant concentrations in the main slug of ASP are $1.2 \%$ and $0.3 \%$. The concentrations of alkali concentration and surfactant concentration in vice slug are $1.0 \%$ and $0.1 \%$. Surfactants used in Daqing are domestic and their cost is much lower than those imported abroad. This large scale strong alkali ASP flooding in Daqing was reported as the highest incremental oil recovery (28\%) in China up to present [62]. However, the economics performance of this field tests is not highest because of scaling and antiscale measures taken.

Chromatographic separation of ASP flooding is generally more serious than laboratory $[74-76,84]$. The chromatographic separation was believed one of the main factors influencing ASP [84]. The appearance order of three components in produced fluid is alkali, polymer, and surfactant [74$76,84]$. The gap between three component varies between $0.02 \mathrm{PV}$ and $0.20 \mathrm{PV}$, indicating the complex of reservoir [62]. Chromatographic separation in weak alkali ASP flooding was not serious as previously believed. This was perhaps one advantage of weak alkali ASP flooding over strong alkali ASP flooding. Tests [74-76] in Daqing oilfield show that the biological surface active agent used as a sacrificial agent compound with ORS41 can reduce ORS detention in the reservoir and reduce the dosage of surface active agent. In one oilfield used biosurfactant, the use of biological surface active agent can reduce the amount of surfactant by about $50 \%$ and reduce by $30 \%$ cost of ASP [39]. Reasons causing different ASP retention are molecular weight of polymer, alkali and surfactant, molecular structure, and the volume difference after hydration. Sacrifice agents could reduce the adsorption of surfactants, but it had no obvious effect on chromatograph separation [62].

Laboratory results show that ASP can make crude oil emulsified seriously. The field experiment also shows that emulsification happens almost in all producers. Almost all good performance wells were seen strong emulsification. Stronger emulsification always goes with lower reduced water cut and more produced oil in producers. Although the emulsion is believed to enhance oil recovery, the serious emulsified produced liquid of ASP flooding brought difficult problems to deal with $[13-15,67,70]$. Daqing oilfield revealed that the ASP flooding produced liquid is different from polymer flooding in produced fluid composition, microstructure, separation characteristics, and oil-water interfacial properties [13-15]. The emulsion stability mechanism is supersaturated stable mechanism and the steric stabilization mechanism [13-15]. Emulsion from strong alkali ASP flooding is more difficult to deal with than weak alkali ASP flooding [62]. Daqing oilfield has developed SP series demulsifies and WS series of water quality stabilizer to solve the problem separation problem liquid of oil and water efficiently. This helps reduce the water disposal cost.

Corrosion and scaling are common problems in field practice of ASP [13-15, 37, 84, 85], (Liang et al. 2011). Field tests suggest that the side effects of alkali cannot be ignored alkali [13-15]. The adverse effects of alkali of ASP include the dosage of polymer significantly increasing for maintaining the required viscosity. Alkali, especially strong alkali, will cause harm to reservoir and make the injection production system scaling seriously. Scaling in weak alkali ASP flooding is much severer than strong alkali ASP flooding $[13-15,62]$. Comparison between strong alkali and weak alkali ASP flooding field test performances is given by Guo et al. [62]. Alkali existence will exacerbate the produced fluid emulsion further, adding difficulty to deal with produced fluid. Though efforts of physics and chemical scale prevention have been taken to prevent scaling and extend the average pump-checking period from 120 days to 162 days, the all pump-checking period is still $50 \%$ shorter than that in the case of polymer flooding [37]. Liu et al. [85] studied alkali ASP's characteristics and countermeasures and found that the scaling of produced fluid scaling has a greater impact on the lift system. After overcoming the scaling and produced fluid handling problems, ASP flooding has entered industrial stage since 2014. Detailed information about produced fluid handing can be seen in literature [86]. Cheng et al. [13-15] introduced the technology breakthrough in antiscaling in ASP flooding in Daqing. The operating cost was reduce by 
72.77\% [13-15], which makes it possible to suffer ultralow oil price. Heavy alkyl benzene sulfonate (HABS) and petroleum sulfonate were employed as the main strong alkali and weak alkali surfactants, respectively [42]. HABS is also used in weak alkali ASP flooding projects recently [57]. Structure and more information about the surfactant ABS/HABS can be seen in $[42,49,57]$. Even when the oil price dropped drastically in 2015 and 2016, there are more and more ASP flooding applications implemented in Daqing. In 2016, there are three new ASP flooding industrial projects in Daqing, and the total number of ASP flooding projects in Daqing oilfield is 22. It should be noted that weak alkali ASP flooding has significant advantage over strong alkali, although strong alkali ASP flooding field tests number was twice of weak alkali [62]. Among the 22 ASP projects in Daqing, most are weak alkali $\left(\mathrm{Na}_{2} \mathrm{CO}_{3}\right)$ ASP flooding, and the previous strong alkali $(\mathrm{NaOH})$ ASP field test block like N-5 block is changing into weak alkali. Almost all new ASP flooding projects in Daqing are weak alkali. In history, $\mathrm{NaOH}$ was selected and given more attention because of the surfactant requirement and in the early stage of ASP flooding two-thirds are $\mathrm{NaOH}$. Much effort has been made to study the scaling and antiscaling as well as produced fluid handing technology and Daqing oilfield is the first and only company in China that has mastered all the technologies in ASP flooding commercial application.

Field test in Daqing oilfield [84] also shows that scaling in weak alkali ASP flooding is much less than strong alkali ASP flooding. In China, all recent ASP flooding field tests are weak alkali except Daqing. In Daqing, both strong alkali and weak alkali ASP flooding are technically applicable after 20 years of continuous research, and it is well accepted until recently that weak alkali ASP flooding is better than strong alkali ASP flooding in both incremental recovery and comprehensive cost $[13-15,62]$. And some previous strong alkali ASP blocks are changed into weak alkali ASP flooding.

As can be seen from Guo et al. [62], whether it is weak alkali or strong alkali of ASP flooding, the incremental recovery is 2 times that of the polymer flooding, and oil production rate is more than one time that of polymer flooding. But the peak rate of oil production of weak alkali is 1.24 times that of strong alkali and 2.17 times that of polymer flooding. The injection production capacity of weak alkali of ASP flooding is higher than strong alkali. Injection pressure keeps stable upward trend in weak alkali ASP flooding, and injection capacity is higher than the strong alkali ASP flooding and polymer flooding. At the stage of chemical flooding, produced fluid of weak alkali ASP flooding decreased more slowly and the decrease extent was smaller. And its fluid producing ability is stronger than the strong alkali ASP and polymer. The lowest water cut of weak alkali fells more than $17 \%$, higher than the strong alkali and polymer. The total incremental recovery of weak alkali and strong alkali ASP is comparable, considering the reservoir complex and petrophysical advantage of the strong alkali referred. Compared with strong alkali, chromatographic separation phenomenon of weak alkali is not serious, showing better synergy between three components. The order of chemical composition of produced liquid of weak alkali is polymer, alkali, and surfactant, but the time interval of alkali and surfactant produced out is only $0.029 \mathrm{PV}$, smaller than strong alkali $[74-76,83]$. It is notable that in B-1-DD strong alkali ASP block [62] there are large amounts of $\mathrm{CO}_{2}$ in brine; thus the chromatographic separation of alkali there is not typical because injected alkali $(\mathrm{NaOH})$ significantly affected the ion balance.

Besides excellence in Daqing oilfield, ASP flooding has also made great progress in Henan, Shengli, and Xinjiang oilfields in China. Another large scale weak alkali field tests being implemented in China is in Henan oilfield. The large scale field tests in Sinopec contain 33 injectors and 35 producers and the reservoir temperature is $81^{\circ} \mathrm{C}$. The average permeability of the reservoir is $543 \mathrm{mD}$. Five-spot well pattern is based on water flooding and the irregular well spacing is $170-260 \mathrm{~m}$. Two ASP slugs are used, $0.8 \%$ $\mathrm{Na}_{2} \mathrm{CO}_{3}, 0.3 \%$ surfactant and $1800 \mathrm{ppm}$ polymer as main ASP slug, and $0.5 \% \mathrm{Na}_{2} \mathrm{CO}_{3}, 0.2 \%$ surfactant, and $1800 \mathrm{ppm}$ polymer. Profile control slugs are also adopted. Surfactant used is mixtures of anionic/cationic surfactants produced in Shanghai [8]. Considering its high temperature $\left(81^{\circ} \mathrm{C}\right)$ high water cut $(97.8 \%)$ and high recovery (53\%) before the field tests, the ASP flooding is very successful with a predicted incremental recovery of $14.6 \%$. At present, the other ASP flooding in ultrahigh temperature $\left(95^{\circ} \mathrm{C}\right)$ is under research in Henan oil field, and organic alkali is used instead inorganic alkali [58]. Laboratory studies were finished and a field test is in schedule in Henan oilfield. The surfactant screening is similar to that in literature [8].

Shengli oilfield has finished two ASP flooding field tests in China [77]. Detailed information about these two field tests can be seen in [5,77, 87-89]. Different from good geological conditions of Daqing oilfield, temperature, salinity of formation, and crude oil viscosity in Shengli are high, making it difficult to attain high viscosity underground. Research shows that, in view of the Shengli oilfield reservoir conditions, the mobility ratio between 2 and 7 can improve recovery greatly. It shows that for a relatively high viscosity oilfield in ASP flooding, it cannot copy the successful experience of Daqing oilfield. The first ASP started in 1992 and finished in 1994 in Gudong [88]. The reservoir temperature is $68^{\circ} \mathrm{C}$ and the in situ oil viscosity is high. There are 4 injectors and 9 producers and the well spacing is $50 \mathrm{~m}$. Average air permeability is $3.818 \mathrm{D}$, and effective permeability is $2.563 \mathrm{D}$. The oil acid number is very high $(3.11 \mathrm{mg} \mathrm{KOH} / \mathrm{g}$ oil), which is beneficial to ASP. Divalent ion $\left(\mathrm{Ca}^{2+}+\mathrm{Mg}^{2+}\right)$ concentration in formation brine is $90 \mathrm{mg} / \mathrm{L}$.This is quite different from low acid value Daqing oil. Imported surfactant (OP-10) together with a petroleum sulphonate CY was used. Imported polymers (3530S) were used. $\mathrm{Na}_{2} \mathrm{CO}_{3}$ was used. The main slug is $0.35 \mathrm{PV}$ and consists of $1.5 \% \mathrm{Na}_{2} \mathrm{CO}_{3}$, $0.2 \%$ OP-10, $0.2 \%$ CY-1, and $1000 \mathrm{ppm} 3530$. The water cut decreased $45 \%$ at most. The final incremental oil recovery was $16.8 \%$ according to updated data. The second large well spacing ASP flooding field test in Shengli was in Gudao West [87]. The test started in 1997 and finished in 2002. The field tests contain 6 injectors and 13 producers, and the well spacing is $212 \mathrm{~m}$. Reservoir permeability is $1520 \mathrm{mD}$. The formation temperature is $69^{\circ} \mathrm{C}$ and underground oil viscosity is $70 \mathrm{mPa} \cdot \mathrm{s}$. The acid value is $1.7 \mathrm{mg} \mathrm{KOH} / \mathrm{g}$ oil. Divalent ion 
$\left(\mathrm{Ca}^{2+}+\mathrm{Mg}^{2+}\right)$ concentration in formation brine is $143 \mathrm{mg} / \mathrm{L}$. The ASP process was conducted in a three-slug sequence, which can be seen in [87].

The final incremental oil recovery in Gudao West was $15.5 \%$ OOIP. The single well water cut dropped $31 \%$ at most. The field water cut dropped from $94.7 \%$ to $84.5 \%$ [90]. These two field tests' incremental oil recovery is less than those in Daqing. The higher temperature, higher divalent ion concentration, higher oil viscosity, and higher acid value may account for the incremental oil recovery difference. Oil composition between Shengli oil and Daqing oil indicated that Daqing oil contained very little asphaltenes (paraffinic crude oil) [48]. These field tests also indicate that factors affecting well response performance include interwell connectivity, geologic structure, sedimentary microfacies, and channeling [90]. Because of the high divalent ion and serious scaling, SP flooding was given more priority than ASP flooding after these two field tests in Shengli oilfield. Until 2016, SP flooding has become one of the major EOR techniques in Shengli and 16 SP flooding projects have been carried out. The average incremental oil recovery is $10.2 \%$, and the annual incremental oil production is more than half of the chemical flooding production there.

Another notable ASP flooding was carried out in Karamay in Xinjiang oilfield (Qi et al., 2000), [87]. It is the first and only ASP flooding carried out in conglomerate reservoir. The field tests contained 4 injectors and 9 producers and the well spacing is $70 \mathrm{~m}$. Three-slug process was designed as follows [87]. The surfactant KPS is a cheap local surfactant developed for the oilfield. Similar to Shengli oilfield, no alkali SP flooding was studied and chosen later after the ASP flooding. In 2011, a large scale SP flooding test containing 18 injectors and 26 producers was carried out in Karamay oilfield [59].

The three-slug scheme in Shengli and Karamay is different from that in Daqing, where four-slug scheme has become a standard practice. The other major difference is alkali used. All ASP flooding tests in Shengli, Karamay, and Henan adopted weak alkali $\left(\mathrm{Na}_{2} \mathrm{CO}_{3}\right)$, while in Daqing, both strong alkali $(\mathrm{NaOH})$ and weak alkali were used. In fact, as stated before, during a long period, $\mathrm{NaOH}$ has been given priority in Daqing. Results from the Daqing oil field in China indicated that surfactant did not produce ultralow water-oil IFT values. However, the addition of $1 \mathrm{wt} . \% \mathrm{NaOH}$ enabled them to reach this condition [10]. In the first 6 pilot tests from 1993 to 1997 in Daqing, 4 is $\mathrm{NaOH}$ based [59, 62]. From 1998 to 2007, 6 larger industrial ASP flooding tests were carried out and 4 are $\mathrm{NaOH}$ based. From 2007 to 2009, 4 more large scale commercial application and demonstration zone blocks were carried out and all four are $\mathrm{NaOH}$ based. After 2012, consensus has been attained that weak alkali is much more economic than strong alkali after summary and comparison of two typical industrial test finished [62]. In July 2013, the first industrial and demonstration weak alkali ASP flooding block in Daqing started ASP injection. This block contains 96 injectors and 96 producers. After 2013, more and more weak alkali ASP flooding blocks were carried out in Daqing. And some previous planned strong alkali ASP flooding blocks were changed into weak alkali ones. In 2016, there are 22
ASP flooding blocks and 18 are weak alkali ones. The reason why weak alkali ASP flooding is selected instead of strong alkali one can be seen in Guo et al. [62]. It may be surprising that in 2015 and 2016 when international oil price is so low there are still so many ASP flooding projects put into use. The master of related technology like antiscaling and produced fluid treatment and measures taken to reduce cost account for this. During industrial field tests stage, the average combined cost including drilling cost of crude oil can be $24-35 \$$ per barrel [13-15]. Some measures have been taken to reduce the drilling cost and surface parts. Using $\mathrm{Na}_{2} \mathrm{CO}_{3}$ as alkali in ASP flooding instead of previously used $\mathrm{NaOH}$ is proven to be of much lower cost and other benefits [62].

\section{Conclusions}

(1) Compared with ordinary polymer HPAM, the hydrophobic associated polymer and comb polymer have advantages like low cost, good stability, and prominent displacement effects. The recovery increases as the oil/water mobility ratio increases both for heterogeneous and homogeneous cores, but incremental oil recovery in heterogeneous cores is higher.

(2) ASP can improve both sweep efficiency and displacement efficiency remarkably due to the low IFT as well as the viscosity and elasticity of polymer which can be accounted for pulling-dragging effect. However, polymer flooding can improve sweep efficiency but the improved displacement efficiency is limited even with elasticity effect. When the reservoir heterogeneity is not serious, ASP mainly enhances oil recovery by enlarging displacement efficiency, while for serious heterogeneous reservoirs, measures should be taken to improve sweep efficiency.

(3) Equilibrium IFT rather than dynamic IFT is used to characterize surfactants in EOR research in China. As for the effects of IFT to displacement effects, it is commonly accepted that lower equilibrium IFT makes higher enhanced oil recovery for the similar equilibrium IFT value, and recovery can be improved by largely reducing dynamic IFT. It is commonly believed that the IFT between oil and water reduced to $10^{-3} \mathrm{~N} / \mathrm{m}$ is the necessary condition of enhancing oil recovery by $20 \%$. However, laboratory studies also showed that $10^{-2} \mathrm{~N} / \mathrm{m}$ IFT can also enhance the recovery of more than $20 \%$, and equilibrium IFT rather than dynamic IFT mainly affects the displacement effects. Classic capillary desaturation curve showed that lower IFT and larger capillary number give lower residual oil saturation and higher displacement efficiency. The difference between remaining and residual oil saturation is often mixed.

(4) Surfactant and alkali can change wettability from oilwet to water-wet. Apart from the reaction of alkali with acid composition in oil, alkali can also react with mineral and clay, changing original clay into sodium type clay which is easy to hydrate. 
(5) Emulsification is common in ASP flooding. Factors affecting emulsification include oil composition, permeability, pore structure, IFT, viscosity, flow rate, and water cut. Alkali facilitates emulsification and strong alkali has bigger emulsification ability than weak alkali. It is believed that emulsification in ASP could contribute to enhancing oil recovery, though its mechanism is worth exploring.

(6) Alkali concentration is the key factor that affects IFT between oil and water, and only when the alkali concentration reaches a certain value can the IFT be reduced to super low. The ASP viscosity is reduced by the increase of alkali concentration, and low alkali ASP has good viscosity but IFT is not lowest, whereas the alkali concentration should be optimized. There is critical ASP viscosity for a certain heterogeneous layer, and only when this critical viscosity is reached could the recovery be enhanced as IFT decreases.

(7) Scaling and erosion problem is very common in ASP flooding field test. In strong alkali ASP flooding pilot test in Daqing oilfield, the main scale type is calcium carbonate and silica scale, while, in weak alkali ASP, the scaling problem is less serious and the main scale type is calcium carbonate. Effective antiscaling lift technology used includes long-plunger shortbarrel tubular pump, little interfere fit progressing cavity pump, and also matched chemical antiscaling technology. The technology breakthrough in scaling makes both strong alkali and weak alkali technically acceptable in Daqing. Scaling is strong alkali ASP flooding is so serious that it affected the economic performance; thus more and more weak alkali ASP flooding is carried out in Daqing.

(8) The important parameters of ASP flooding slug combination listed in sequence are polymer concentration, surfactant concentration, slug size, and alkali concentration. Four slugs consisting of preflush polymer slug, main ASP slug, second ASP slug, and postflush protection slug give optimal displacement effects. The main slug of ASP is usually $0.2-0.5 \mathrm{PV}$, and determined by laboratory and numerical optimization, and 0.30 PV was used in Daqing oilfield pilot test while $0.35 \mathrm{PV}$ for Shengli Oilfield, and the average main slug of 32 pilot tests in the world is 0.308 PV. Separate injection has better displacement effect than overall injection in serious heterogeneous reservoir.

(9) Chromatographic separation was obvious in pilot tests, and both laboratory study and pilot tests indicate that polymer is produced first, then followed by alkali and surfactant being the last one to be produced at the production well. And the adsorption amount sequence was surfactant, alkali, and polymer. Weak alkali ASP chromatographic separation is less serious than strong alkali ASP.

(10) ASP flooding has entered industrial application in Daqing since 2014 and there are currently 22 blocks containing 7231 injectors and producers in 2016. ASP flooding practice in China provides a very good way to use enhanced oil recovery to meet the challenges of low oil recovery and make profit.

\section{Disclosure}

This paper was revised in the paper presented in EAGE organized 18th European Symposium on Improved Oil Recovery (IOR2015) in Dresden, Germany, 14-16 April 2015.

\section{Competing Interests}

The authors declare that there is no conflict of interests regarding the publication of this paper.

\section{Acknowledgments}

This work was financially supported by the Scientific Research Foundation of China University of Petroleum, Beijing (no. 2462013YJRC033), National Natural Science Foundation Project (no. 51374221; No. 51604285), and Beijing Natural Science Foundation (no. 316404).

\section{References}

[1] A. Mandal, "Chemical flood enhanced oil recovery: a review," International Journal of Oil, Gas and Coal Technology, vol. 9, no. 3, pp. 241-264, 2015.

[2] S. Mishra, A. Bera, A. Mandal, S. Mishra, A. Bera, and A. Mandal, "Effect of polymer adsorption on permeability reduction in enhanced oil recovery," Journal of Petroleum Engineering, vol. 2014, Article ID 395857, 9 pages, 2014.

[3] M. Y. Khan, A. Samanta, K. Ojha, and A. Mandal, "Design of alkaline/surfactant/polymer (ASP) slug and its use in enhanced oil recovery," Petroleum Science and Technology, vol. 27, no. 17, pp. 1926-1942, 2009.

[4] S. Kumar and A. Mandal, "Studies on interfacial behavior and wettability change phenomena by ionic and nonionic surfactants in presence of alkalis and salt for enhanced oil recovery," Applied Surface Science, vol. 372, pp. 42-51, 2016.

[5] J. J. Sheng, "A comprehensive review of alkaline-surfactantpolymer (ASP) flooding," Asia-Pacific Journal of Chemical Engineering, vol. 9, no. 4, pp. 471-489, 2014.

[6] Y. Zhu, X. Liu, and J. Fan, "Developments of ASP/SP flooding formulations for Huabei fault block reservoir," in Proceedings of the SPE/IATMI Asia Pacific Oil \& Gas Conference and Exhibition, SPE-176117-MS, Bali, Indonesia, October 2015.

[7] W. Demin, W. Gang, W. Wenxiang, X. Huifen, and Y. Hongjun, "The influence of viscoelasticity on displacement efficiencyfrom micro to macro scale," in Proceedings of the SPE-109016MS. SPE Annual Technical Conference and Exhibition, Anaheim, Calif, USA, November 2007.

[8] G. Li, J. Zhao, Y. Sun, H. Ji, J. Hao, and Y. Tao, "ASP system performance under condition of $\mathrm{NaCl}$ as partly substitute of $\mathrm{NaOH}$,' Inner Mongolia Petrochemical Industry, no. 5, 2014.

[9] F. D. Martin, J. C. Oxley, and H. Lim, "Enhanced recovery of a 'J' sand crude oil with a combination of surfactant and alkaline chemicals," in Proceedings of the SPE Annual Technical 
Conference and Exhibition, SPE-14293-MS, Las Vegas, Nev, USA, September 1985.

[10] C. S. Gregersen, M. Kazempour, and V. Alvarado, "ASP design for the Minnelusa formation under low-salinity conditions: impacts of anhydrite on ASP performance," Fuel, vol. 105, pp. 368-382, 2013.

[11] M. Delshad, C. Han, F. K. Veedu, and G. A. Pope, "A simplified model for simulations of alkaline-surfactant-polymer floods," Journal of Petroleum Science and Engineering, vol. 108, pp. 1-9, 2013.

[12] L. Co, Z. Zhang, Q. Ma et al., "Evaluation of functionalized polymeric surfactants for EOR applications in the Illinois Basin," Journal of Petroleum Science and Engineering, vol. 134, pp. 167-175, 2015.

[13] J. C. Cheng, Q. G. Wang, W. F. Zhou, S. Li, T. Cheng, and G. Zhou, "Synthesis and application of silicon scale inhibitor SY-KD under the ASP flooding system," Chemical Journal of Chinese Universities, vol. 35, no. 2, pp. 332-337, 2014.

[14] J. Cheng, J. Wu, and J. Hu, "Key theories and technologies for enhanced oil recovery of alkaline/surfactant/polymer flooding," Acta Petrolei Sinica, vol. 35, no. 2, pp. 310-318, 2014.

[15] C. Jiecheng, Z. Wanfu, W. Qingguo et al., “Technical breakthrough in production engineering ensures economic development of ASP flooding in Daqing Oilfield," in Proceedings of the SPE Asia Pacific Oil \& Gas Conference and Exhibition, SPE171506-MS, Adelaide, Australia, October 2014.

[16] A. Clarke, A. M. Howe, J. Mitchell, J. Staniland, and L. A. Hawkes, "How viscoelastic-polymer flooding enhances displacement efficiency," SPE Journal, vol. 21, no. 3, pp. 675-687, 2016.

[17] G. Z. Liao, K. L. Wang, and W. H. Yan, "Experimental study the effect of mobility ratio on the displacement efficiency of chemical flooding," Petroleum Geology \& Oilfield Development in Daqing, vol. 20, no. 2, pp. 14-16, 2001.

[18] I. Chatzis and N. R. Morrow, "Correlation of capillary number relationships for sandstone," Society of Petroleum Engineers Journal, vol. 24, no. 5, pp. 555-562, 1984.

[19] R. A. Fulcher, The Effect of the Capillary Number and Its Constituents on Two-Phase Relative Permeabilities, The Pennsylvania State University, 1983.

[20] P. Lv, "Experimental Study on the factors affecting sweep efficiency," in Petroleum Exploration and Development, vol. 4, pp. 54-60, 1985.

[21] V. H. Nguyen, P. A. Sheppard, A. M. Knackstedt et al., "The effects of displacement rate and wettability on imbibition relative permeabilities," in Proceedings of the 2005 SPE Annual Technical Conference and Exhibition, pp. 1-12, Dallas, Tex, USA, 2005.

[22] P. Lv and P. W. Liu, "Experiment research on capillary number effect on percolation characteristics," Mechanics and Engineering, no. 6, pp. 44-46, 1984.

[23] P. Lv, "Experiment research on capillary number effect on percolation characteristics," Journal of Hydrodynamics, no. 1, pp. 75-80, 1987.

[24] A. A. Olajire, "Review of ASP EOR (alkaline surfactant polymer enhanced oil recovery) technology in the petroleum industry: prospects and challenges," Energy, vol. 77, pp. 963-982, 2014.

[25] Z. W. Jia, Q. Y. Yang, M. Yuan, Z. Hou, and L. Zhang, "Experimental study on influential factors of ASP displacement efficiency in Daqing Oilfield," Acta Petrolei Sinica, vol. 27, S1, pp. 101-105, 2006.
[26] F. Yang, Y. Guo, X. Zhang, and P. Luo, "Enhanced oil recovery technology of alkaline/surfactant/hydrophobically associating polyacrylamide flooding after polymer flooding," Shiyou Xuebao/Acta Petrolei Sinica, vol. 35, no. 5, pp. 908-913, 2014.

[27] D. Alexis, D. Varadarajan, D. H. Kim, G. Winslow, and T. Malik, "Evaluation of innovative associative polymers for low concentration polymer flooding," in Proceedings of the SPE Improved Oil Recovery Conference, Tulsa, Okla, USA, April 2016.

[28] J.-H. Luo, R.-Y. Bu, H.-J. Zhu, P.-M. Wang, and Y.-Z. Liu, "Property and application of comb-shape polyacrylamide," Shiyou Xuebao/Acta Petrolei Sinica, vol. 25, no. 2, pp. 65-73, 2004.

[29] B. N. Riley and H. D. Peter, "Polymer flooding review," Journal of Petroleum Technology, vol. 39, no. 12, pp. 1-5, 1987.

[30] J. X. Tang, T. L. Chen, and J. J. He, "An experimental study on relative permeability curves of polymer flooding," Acta Petrolei Sinica, vol. 18, no. 1, pp. 81-84, 1997.

[31] H. Koh, V. B. Lee, and G. A. Pope, "Experimental investigation of the effect of polymers on residual oil saturation," in Proceedings of the SPE Improved Oil Recovery Conference 2016, Tulsa, Okla, USA, April 2016.

[32] D. Wang, G. Wang, and H. Xia, "Large scale high viscouselastic fluid flooding in the field achieves high recoveries," in Proceedings of the SPE Enhanced Oil Recovery Conference "From Science to Success: More, Faster, Greener, Cheaper" (EORC '11), pp. 831-837, Kuala Lumpur, Malaysia, July 2011.

[33] W. Deming, X. Huifen, Y. Shuren, and W. Gang, "The influence of visco-elasticity on micro forces and displacement efficiency in pores, cores and in the field," in Proceedings of the SPE EOR Conference at Oil \& Gas West Asia, SPE-127453-MS, Muscat, Oman, April 2010.

[34] D. M. Wang, J. C. Cheng, and Q. Y. Yang, "Viscous-elastic polymer can increase micro-scale displacement efficiency in cores," Acta Petrolei Sinica, vol. 21, no. 5, pp. 45-51, 2000.

[35] R. S. Seright, T. Fan, K. Wavrik, and R. de Carvalho Balaban, "New insights into polymer rheology in porous media," $S P E$ Journal. SPE-129200-PA, vol. 16, no. 1, 2011.

[36] R. Reichenbach-Klinke, A. Stavland, D. Strand, B. Langlotz, and G. Brodt, "Can associative polymers reduce the residual oil saturation?" in Proceedings of the SPE EOR Conference at Oil and Gas West Asia (OGWA '16), Muscat, Oman, March 2016.

[37] Y. Zhu, Q. Hou, W. Liu, D. Ma, and G. Liao, "Recent progress and effects analysis of ASP flooding field tests," in Proceedings of the 18th SPE Improved Oil Recovery Symposium, SPE-151285MS, pp. 1-8, Tulsa, Okla, USA, April 2012.

[38] J.-J. Ge, G.-C. Zhang, P. Jiang, and M.-Q. Sun, "Development of surfactants as chemicals for EOR," Oilfield Chemistry, vol. 24, no. 3, pp. 287-292, 2007.

[39] D. S. Li, G. Z. Liao, and L. Yang, "The application studies of biosurfactant as sacrificial adsorbate in ASP flooding," Petroleum Exploration and Development, no. 2, pp. 106-109, 2002.

[40] Y. Li, W. Zhang, B. Kong et al., "Mixtures of anionic/cationic surfactants: a new approach for enhanced oil recovery in lowsalinity, high-temperature sandstone reservoir," SPE Journal, vol. 21, no. 4, pp. 1164-1177, 2016.

[41] Q. Qi, G. Hongjun, L. Dongwen, and D. Ling, "The pilot test of ASP combination flooding in Karamay oil field," in Proceedings of the International Oil and Gas Conference and Exhibition in China, pp. 1-10, Beijing, China, November 2000.

[42] Q. Hou, D. Guo, and O. Jian, "Study on the ASP switchable surfactant for Daqing oilfield," in Proceedings of the SPE EOR 
Conference at Oil and Gas West Asia, SPE-179793-MS, Muscat, Oman, March 2016.

[43] Y. M. Chen, H. Wang, and J. Y. Yu, "Research advance of dynamic interfacial tension behavior in chemical flooding," Acta Petrolei Sinica, vol. 22, no. 4, pp. 97-103, 2001.

[44] K. C. Taylor, B. F. Hawkins, and M. R. Islam, "Dynamic interfacial tension in surfactant enhanced alkaline flooding," Journal of Canadian Petroleum Technology, vol. 29, no. 1, pp. 50$55,1990$.

[45] H. B. Li and Z. H. Chen, "Characteristics of interfacial tension and oil displacement efficiency with alkaline-surfactantpolymer flooding technology," Acta Petrolei Sinica, vol. 27, no. 5, pp. 96-98, 2006.

[46] J. Li, W. Wang, and Y. Gu, "Dynamic interfacial tension and oil shrinking effect of crude oil in alkaline solutions," in Proceedings of the SPE Petroleum Society's Canadian International Petroleum Conference, pp. 1-9, Alberta, Canada, 2003.

[47] H.-F. Xia, C.-Z. Liu, J.-R. Hou, X.-A. Yue, W.-L. Song, and Z.C. Liu, "Effect of viscoelastic behavior and interfacial activity of ASP combinational flooding solution on oil displacement efficiency," Oilfield Chemistry, vol. 20, no. 1, pp. 61-64, 2003.

[48] M. Li, M. Lin, Z. Wu, and A. A. Christy, "The influence of $\mathrm{NaOH}$ on the stability of paraffinic crude oil emulsion," Fuel, vol. 84, no. 2-3, pp. 183-187, 2005.

[49] Y. Zhu and L. Ming, "Effects of crude oil components on the interfacial tension between oil and surfactant solutions," in Proceedings of the SPE Asia Pacific Enhanced Oil Recovery Conference, SPE-174593-MS, Kuala Lumpur, Malaysia, August 2015.

[50] Z.-G. Cui, W.-H. Zou, X.-F. Sun, T.-L. Zhang, and D.-G. Zhang, "The interfacial tension of alkaline/heavy alkylbenzene sulfonate/crude oil systems," Oilfield Chemistry, vol. 16, no. 2, pp. 153-157, 1999.

[51] Y. Y. Zhu, P. P. Shen, and Z. Wang, "Synthesis of alkylbenzene sulfonate surfaetants used for ASP combination flooding," Petroleum Exploration and Development, S1, pp. 17-20, 2004.

[52] L. Q. Qi, Z. Liu, C. Z. Yang et al., "Deep research on the experimental curve of capillary number," Petroleum Geology \& Oilfield Development in Daqing, vol. 28, no. 6, pp. 247-251, 2009.

[53] L. Q. Qi, H. Q. Zhu, Y. P. Sun et al., "Recommended low concentration surfactant system for ASP flooding," Petroleum Geology \& Oilfield Development in Daqing, vol. 29, no. 3, pp. 143-149, 2010.

[54] T. R. French and T. E. Burchfield, "Design and optimization of alkaline flooding formulations," in Proceedings of the SPE/DOE Enhanced Oil Recovery Symposium, SPE-20238-MS, Tulsa, Okla, USA, 1990.

[55] S. Himanshu, J. Lu, U. P. Weerasooriya, G. A. Pope, and K. K. Mohanty, "Adsorption in chemical floods with ammonia as the alkali," in Proceedings of the SPE Improved Oil Recovery Conference, vol. SPE-179682-MS, Tulsa, Okla, USA, April 2016.

[56] J. J. Sheng, "Investigation of alkaline-crude oil reaction," Petroleum, vol. 1, no. 1, pp. 31-39, 2015.

[57] Z. Youyi, C. Fengying, B. Ziwu, W. Zhe, W. Hongzhuang, and Z. Shumei, "Studies on ASP flooding formulations based on alkylbenzene sulfonate surfactants," in Proceedings of the SPE Asia Pacific Oil \& Gas Conference and Exhibition, vol. SPE171433-MS, Adelaide, Australia, October 2014.

[58] F. Zhao, Y. Ma, J. Hou, J. Tang, and D. Xie, "Feasibility and mechanism of compound flooding of high-temperature reservoirs using organic alkali," Journal of Petroleum Science and Engineering, vol. 135, pp. 88-100, 2015.
[59] Y. Zhu, "Current developments and remaining challenges of chemical flooding EOR techniques in China," in Proceedings of the SPE Asia Pacific Enhanced Oil Recovery Conference (EORC '15), pp. 21-38, Kuala Lumpur, Malaysia, August 2015.

[60] J. R. Hou, Z. C. Liu, M. Z. Dong, X. A. Yue, and J. Z. Yang, “Effect of viscosity of alkaline/surfactant/polymer (ASP) solution on enhanced oil recovery in heterogeneous reservoirs," Journal of Canadian Petroleum Technology, vol. 45, no. 11, pp. 27-33, 2006.

[61] H. Sharma, S. Dufour, G. W. P. P. Arachchilage, U. Weerasooriya, G. A. Pope, and K. Mohanty, "Alternative alkalis for ASP flooding in anhydrite containing oil reservoirs," Fuel, vol. 140, pp. 407-420, 2015.

[62] H. Guo, Y. Li, Y. Gu, F. Wang, and Z. Yuliang, "Comparison of strong alkali and weak alkali ASP flooding pilot tests in daqing oilfield," in Proceedings of the SPE Improved Oil Recovery Conference, Tulsa, Okla, USA, April 2016.

[63] S. Huang and M. Dong, "Alkaline/surfactant/polymer (ASP) flood potential in southwest Saskatchewan oil reservoirs," Journal of Canadian Petroleum Technology, vol. 43, no. 12, 2004.

[64] X.-J. Wang and Q.-G. Wang, "A study on inorganic scale formed and scale removing fluid used in production wells of ASPflooding reservoirs," Oilfield Chemistry, vol. 20, no. 1, pp. 1-3, 2003.

[65] P. Li, Z.-F. Cheng, X.-J. Wang, Q.-P. Liu, and S.-L. Ding, "Forming mechanism and prediction method of silica scaling in oil wells with alkaline-surfactant-polymer flooding," Acta Petrolei Sinica, vol. 24, no. 5, pp. 63-66, 2003.

[66] S.-J. Li, Z.-Y. Yang, K.-P. Song, and W.-L. Kang, "Effect of crude oil emulsion on enhanced oil recovery in alkaline surfactant polymer flooding," Acta Petrolei Sinica, vol. 24, no. 5, pp. 71-73, 2003.

[67] F.-S. Zhang, Y.-Q. Zhang, J.-C. Cheng, J.-L. Li, and R. Song, "Relation between composition of the crude oil and demulsification of the liquid produced by ASP flooding and polymer flooding," Acta Petrolei Sinica (Petroleum Processing Section), vol. 24, no. 1, pp. 117-120, 2008.

[68] J. Lu, P. J. Liyanage, S. Solairaj et al., "New surfactant developments for chemical enhanced oil recovery," Journal of Petroleum Science and Engineering, vol. 120, pp. 94-101, 2014.

[69] J. J. Taber, F. D. Martin, and R. S. Seright, "EOR screening criteria revisited-part 1: introduction to screening criteria and enhanced recovery field projects," SPE Reservoir Engineering, vol. 12, no. 3, pp. 189-198, 1997.

[70] A. Weatherill, "Surface development aspects of AlkaliSurfactant-Polymer (ASP) flooding," in Proceedings of the International Petroleum Technology Conference (IPTC '09), Doha, Qatar, December 2009.

[71] H. B. Li, "An experimental study on oil displacement efficiency of ASP combinational flooding solution in relation to core permeability," Oilfield Chemistry, vol. 01, pp. 67-69, 2007.

[72] Z. L. Zhang, Z. H. Wang, S. Y. Wang et al., "ASP flooding system for reservoir strata Saertu of Hongyuan oil fields," Oilfield Chemistry, no. 4, pp. 353-354, 2000.

[73] W. X. Wu, J. R. Hou, and W. Z. Lu, "An experimental study on injection schedule of ASP flooding solutions for Daqing oil fields by physical simulation," Oilfield Chemistry, no. 4, pp. 6366, 1998.

[74] D. S. Li, J. R. Hou, and R. J. Xu, "Advances in laboratory investigations on microbial enhanced oil recovery," Oilfield Chemistry, no. 4, pp. 358-361, 2001. 
[75] D.-S. Li, Q. Jia, and X.-H. Chen, "A study on component retention in reservoirs during ASP flooding field trials at Daqing," Oilfield Chemistry, vol. 18, no. 4, pp. 362-366, 2001.

[76] Z.-Q. Li, J. Hou, X.-L. Cao, and H.-L. Yao, "Optimizing design of injection-production parameters of ASP flooding," Journal of the University of Petroleum, vol. 25, no. 2, pp. 50-53, 2001.

[77] Q. Zhijian, Z. Yigen, Z. Xiansong, and D. Jialin, "A successful ASP flooding pilot in Gudong oil field," in Proceedings of the SPE/DOE Improved Oil Recovery Symposium, vol. SPE-39613MS, Tulsa, Okla, USA, April 1998.

[78] P. Jiang, J. J. Ge, G. C. Zhang et al., "Influence factor on oil recovery efficiency for chemical flooding of heavy oil reservoir," Journal of China University of Petroleum (Edition of Natural Science), no. 2, pp. 166-171, 2011.

[79] P.-P. Shen, S.-Y. Yuan, B.-R. Deng, J. Song, and K.-Y. Shen, "Influence factors of oil displacement efficiency and sweep efficiency in chemical flooding," Petroleum Exploration and Development, 2004.

[80] X. F. Li, R. Chen, N. M. Zhang et al., "Synthesis of poly-nalkylacrylates as pour point depressants for petroleum products," Oilfield Chemistry, no. 4, pp. 369-373, 2000.

[81] W. D. Liu, L. Z. Li, Z. X. Tong et al., "The study of flooding mechanism of Alkali/Polymer/Surfactant in Daqing oilfield," Journal of Chongqing University (Natural Science Edition), vol. 23, no. 1, pp. 119-121, 2000.

[82] J. L. Wang, P. P. Shen, Y. Z. Chen, X. Jia, and Z.-B. Zhang, "3-D physical modeling of enhanced oil recovery by alkly-safactantpolymer flooding," Acta Petrolei Sinica, vol. 26, no. 5, pp. 61-66, 2005.

[83] J. Sheng James, Modern Chemical Enhanced Oil Recovery, Theory and Practice, Elsevier, Oxford, UK, 2011.

[84] J.-C. Cheng, D.-M. Wang, Q. Li, and Z.-Y. Yang, "Field test performance of alkaline surfactant polymer flooding in Daqing oil field," Acta Petrolei Sinica, vol. 23, no. 6, p. 37, 2002.

[85] D. S. Liu, J. L. Li, T. D. Li et al., "Scaling characteristics of silicon and anti-scaling measures in ASP flooding with alkali," Acta Petrolei Sinica, no. 5, pp. 139-141, 2007.

[86] J. Cheng, D. Wu, W. Liu et al., "Field application of chelatants in the handling of ASP-flooding produced fluid," SPE Projects, Facilities and Construction, vol. 6, no. 3, pp. 115-123, 2011.

[87] H. L. Chang, Z. Q. Zhang, Q. M. Wang et al., "Advances in polymer flooding and alkaline/surfactant/polymer processes as developed and applied in the People's Republic of China," JPT, Journal of Petroleum Technology, vol. 58, no. 2, 2006.

[88] S. Wanchao, Y. Chengzhi, H. Dakuang, Q. Zhijian, W. Baoyu, and J. Wenluo, "Alkaline-surfactant-polymer combination flooding for improving recovery of the oil with high acid value," in Proceedings of the International Meeting on Petroleum Engineering, vol. SPE-29905-MS, Beijing, China, November 1995.

[89] C. Wang, B. Wang, X. Cao, and H. Li, "Application and design of alkaline-surfactant-polymer system to Close Well Spacing pilot Gudong oilfield," in Proceedings of the Proceedings of 67th Annual Western Regional Meeting, pp. 605-618, Long Beach, Calif, USA, June 1997.

[90] X.-L. Cao, H.-Q. Sun, Y.-B. Jiang, X.-S. Zhang, and L.-L. Guo, "Enlarged field test on ASP-flood at East district of Gudao oil field," Oilfield Chemistry, vol. 19, no. 4, pp. 350-353, 2002. 

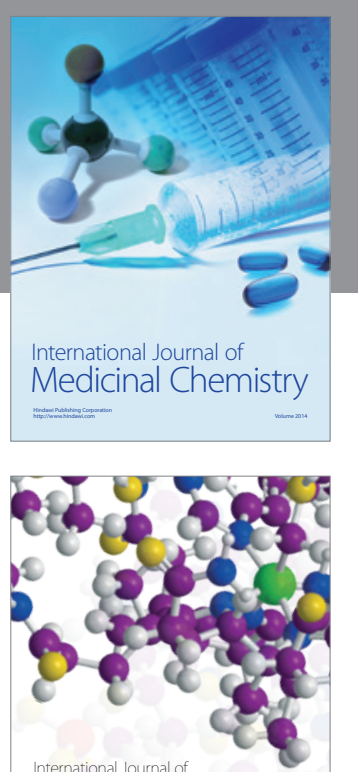

Carbohydrate Chemistry

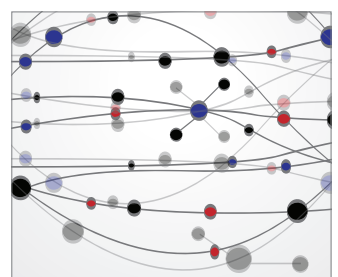

The Scientific World Journal
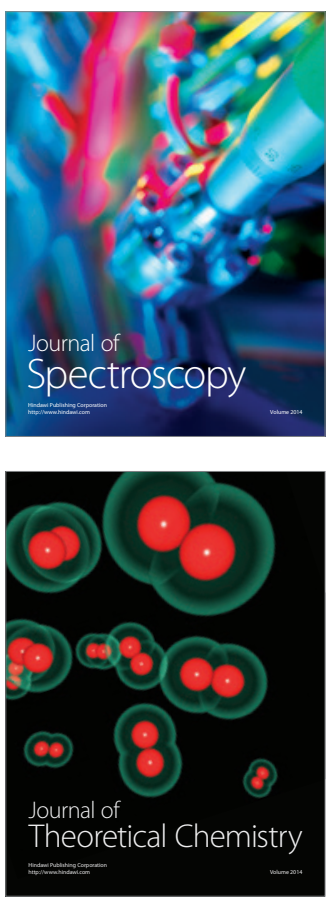
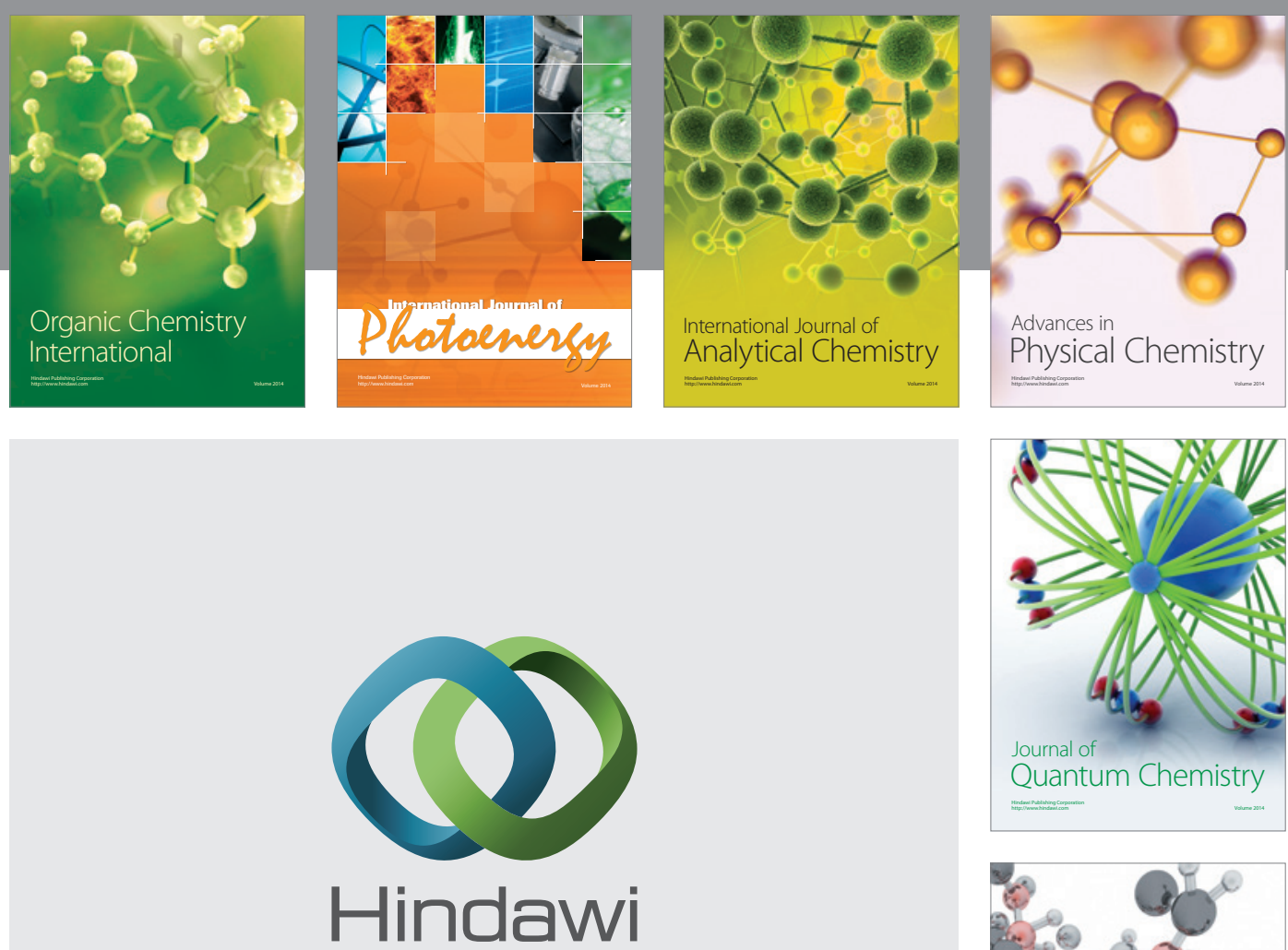

Submit your manuscripts at

https://www.hindawi.com

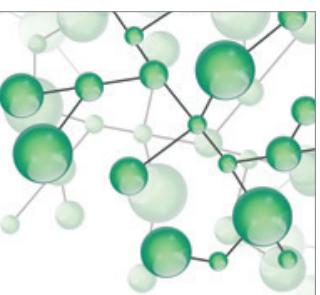

International Journal of

Inorganic Chemistry
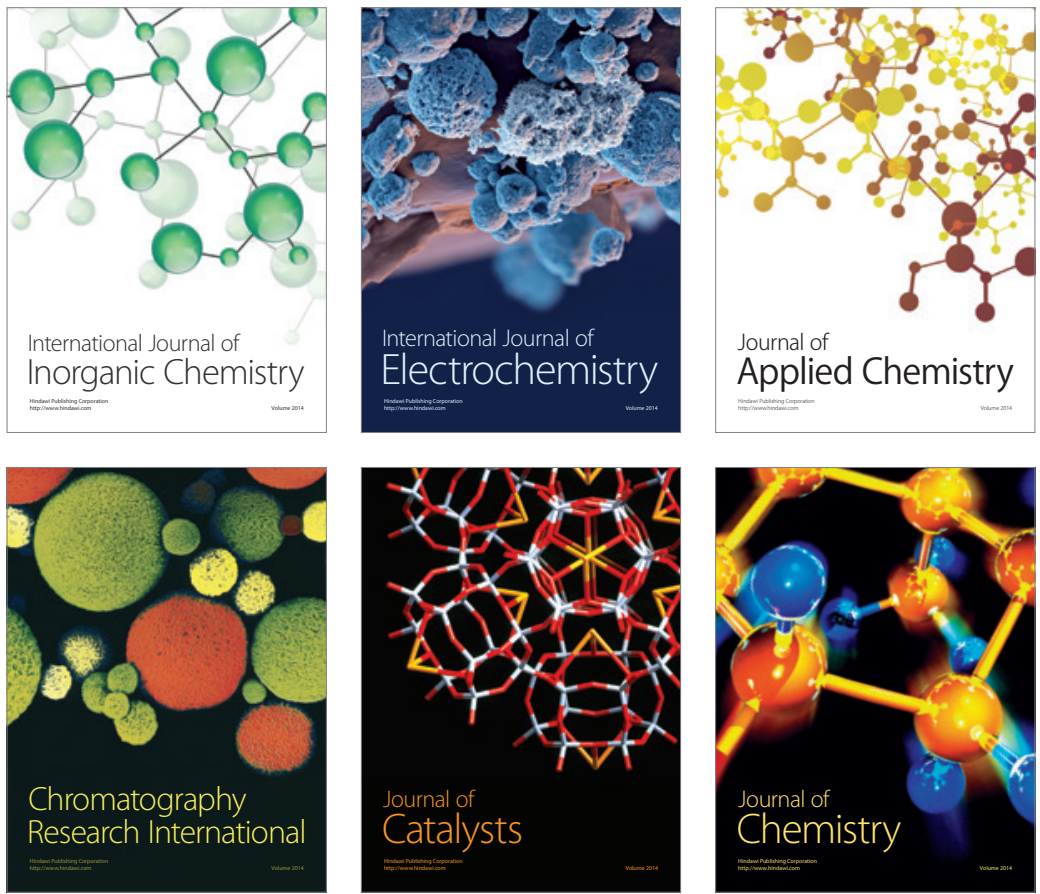

Journal of

Applied Chemistry
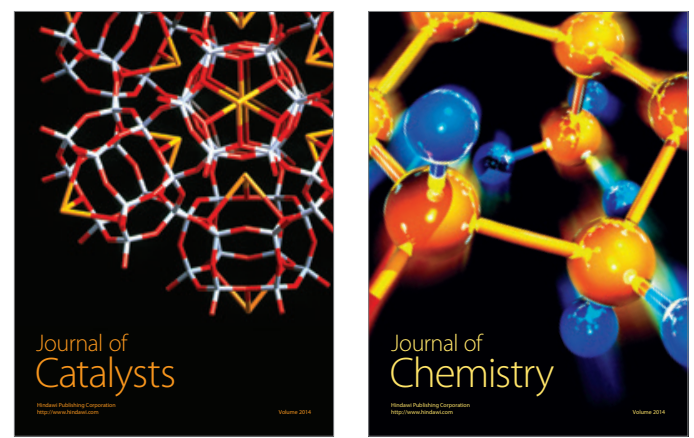
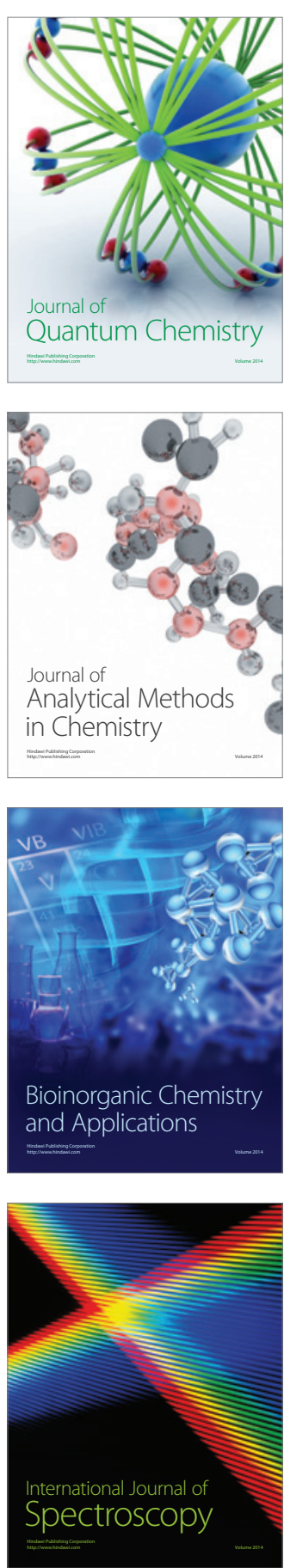